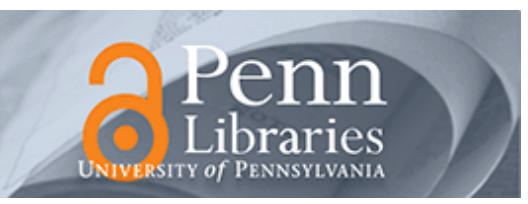

University of Pennsylvania ScholarlyCommons

$11-2003$

\title{
Mapping a Course for Improved Student Learning: How Innovative Schools Systematically Use Student Performance Data to Guide Improvement
}

Jonathan A. Supovitz

University of Pennsylvania, JONS@GSE.UPENN.EDU

Valerie Klein

University of Pennsylvania

Follow this and additional works at: https://repository.upenn.edu/cpre_researchreports

Part of the Curriculum and Instruction Commons, Educational Assessment, Evaluation, and Research Commons, Educational Leadership Commons, Educational Methods Commons, and the Teacher Education and Professional Development Commons

\section{Recommended Citation}

Supovitz, Jonathan A. and Klein, Valerie. (2003). Mapping a Course for Improved Student Learning: How Innovative Schools Systematically Use Student Performance Data to Guide Improvement. CPRE Research Reports.

Retrieved from https://repository.upenn.edu/cpre_researchreports/39

View on the CPRE website.

This paper is posted at ScholarlyCommons. https://repository.upenn.edu/cpre_researchreports/39

For more information, please contact repository@pobox.upenn.edu. 


\title{
Mapping a Course for Improved Student Learning: How Innovative Schools Systematically Use Student Performance Data to Guide Improvement
}

\author{
Abstract \\ To be useful to teachers and school leaders, test data must provide more than just a destination. Student \\ performance results must also provide guidance that informs educators that they are moving in the right \\ direction, while providing interactive and recursive feedback for mid-course adjustments. In order for \\ student performance data to be useful to teachers and school leaders, and to make it worthwhile for \\ them to make the extensive efforts necessary to learn to interpret and act upon what they learn, data \\ feedback systems must rely on multiple sources of data collected and analyzed at regular intervals. \\ This report is about building better roadmaps for teachers and school leaders in order to guide their \\ instructional decision-making. The data required for more precise decision-making come from \\ systematically exploiting a variety of student performance data at both the individual classroom and \\ school levels. Rather than just relying on one individual test to provide guidance, innovative school leaders \\ are building more comprehensive systems of assessments that provide better interim information from \\ multiple perspectives. Through more sophisticated data systems, teachers and school leaders can foster \\ a more inquiryoriented approach that involves ongoing and sustained investigations into the kinds of \\ teaching that produce more powerful student learning. In this report, we show how innovative teachers \\ and school leaders are creatively using their data to help guide their strategic decisions. Through their \\ examples, we develop and describe a theory of what a system of school data use might look like.

\section{Disciplines} \\ Curriculum and Instruction | Educational Assessment, Evaluation, and Research | Educational Leadership | \\ Educational Methods I Teacher Education and Professional Development

\section{Comments} \\ View on the CPRE website.
}




\title{
Mapping a Course for Improved Student Learning: How Innovative Schools Systematically Use Student Performance Data to Guide Improvement
}

\author{
Jonathan A. Supovitz \\ Valerie Klein
}

\begin{abstract}
November 2003
Consortium for Policy Research in Education University of Pennsylvania Graduate School of Education
\end{abstract}





\section{Contents}

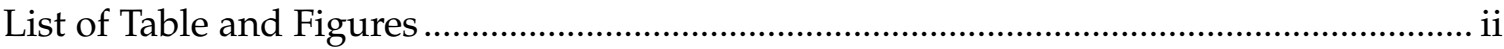

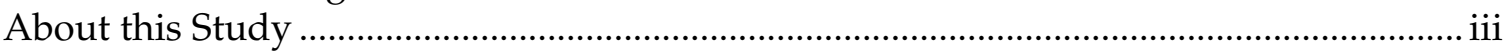

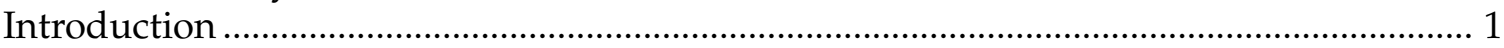

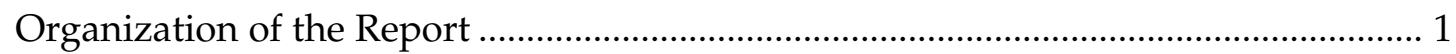

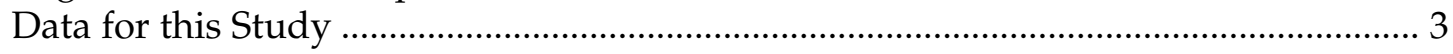

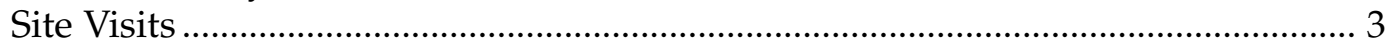

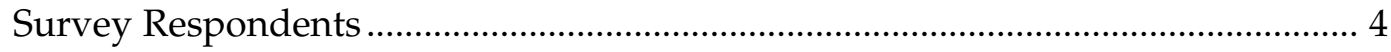

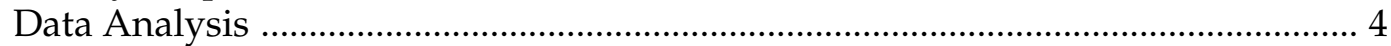

Sources of Student Performance Data ……........................................................................ 5

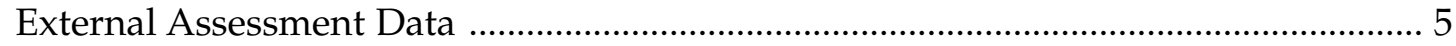

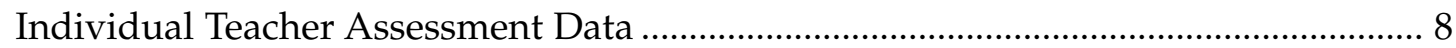

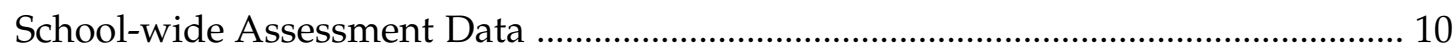

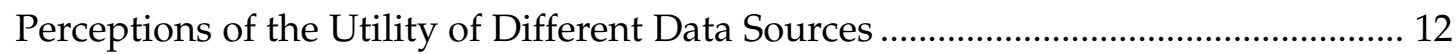

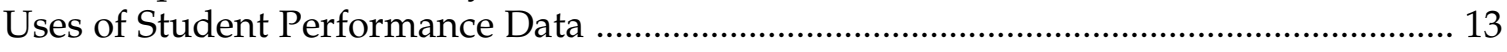

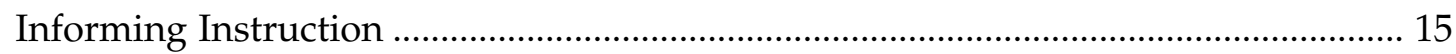

Using Student Performance Data to Identify Lesson Objectives .......................... 16

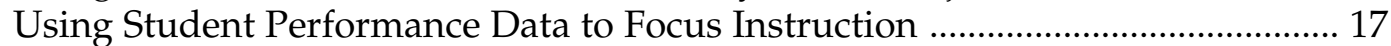

Using Student Performance Data to Align Lessons with Standards ..................... 18

Developing Assistance Plans for Low-performing Students ...................................... 19

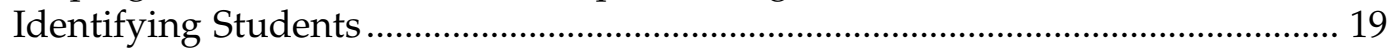

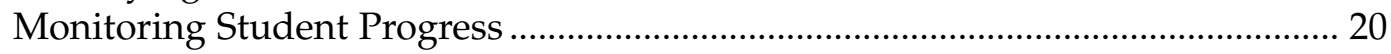

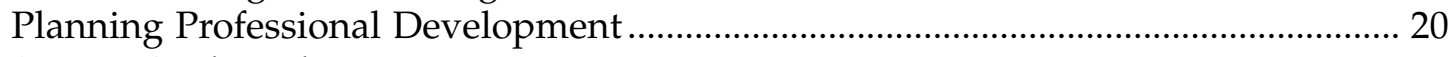

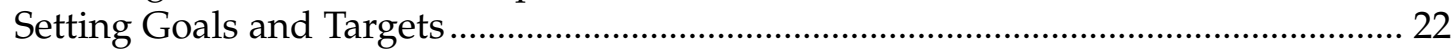

Setting Ambitious Annual Improvement Goals ..................................................... 24

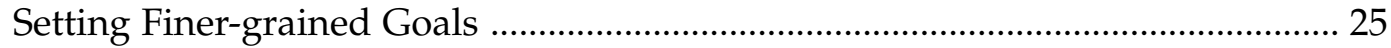

Making School Improvement Goals Public ........................................................... 26

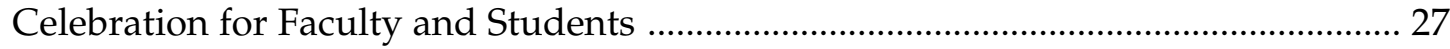

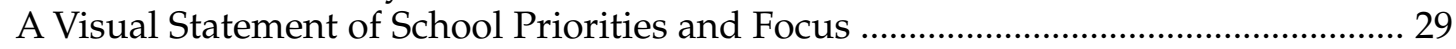

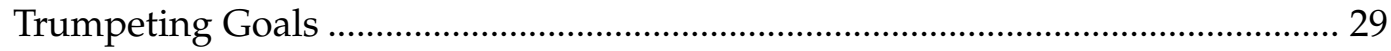

Tracking Students in Need of Additional Support ............................................. 30

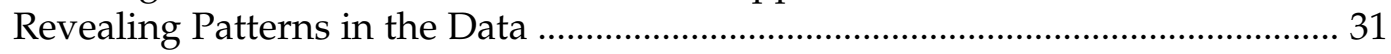

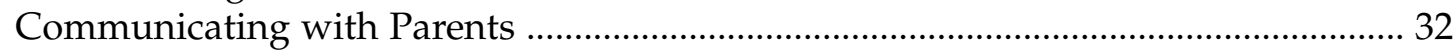

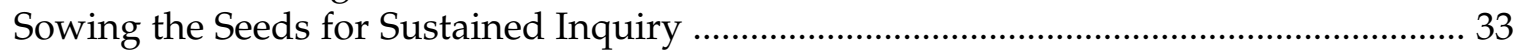

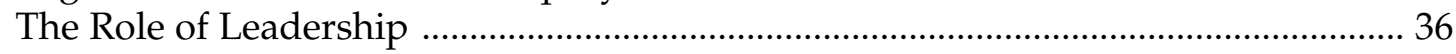

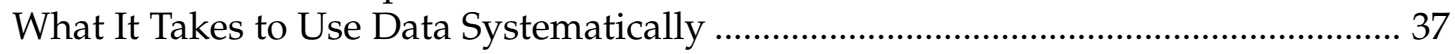

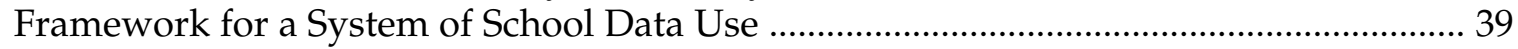

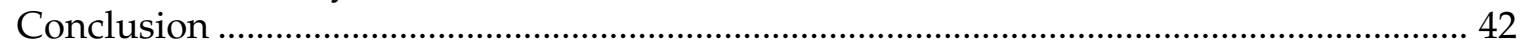

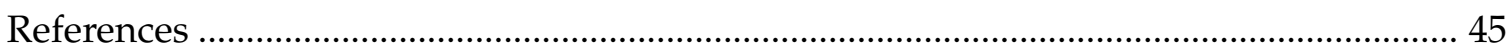

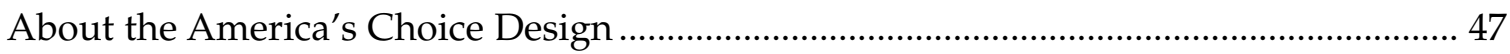

About CPRE's Evaluation of America's Choice ............................................................... 48

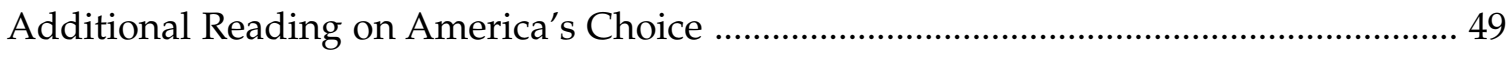




\section{List of Table and Figures}

Table 1. Sources and Uses of Student Performance Data ................................................. 40

Figure 1. School Leaders' Perceptions of the Usefulness of External Test Data ................. 8

Figure 2. Perceived Utility of Different Kinds of Assessment Data .................................. 13

Figure 3. Presentation of School Goals at Jackson Middle School ...................................... 29

Figure 4. School Goals and Progress at Jackson Middle School ......................................... 30

Figure 5. Principal's Conference Room at Parker Middle School ...................................... 30

Figure 6. Tracking At-risk Students at Parker Middle School ............................................ 31

Figure 7. Classroom Running Records Performance at King Elementary School ............ 31

Figure 8. Interplay of the Three Data Sources ................................................................... 41 


\section{About this Study}

This study is an outgrowth of the Consortium for Policy Research in Education's (CPRE) ongoing evaluation of the features and effects of the America's Choice comprehensive school reform model. America's Choice is developed and operated by the National Center on Education and the Economy. For this study, we have capitalized on our access to America's Choice schools in order to examine how a handful of innovative schools are using a variety of student performance data to improve the instruction of teachers and the school organization's support for instructional improvement. Through our research in these schools and characterization of their uses of student performance data, we have developed a theory of systematic school data use. More details about the America's Choice model and CPRE's evaluation efforts are provided at the end of this report. 


\section{Introduction}

If a little knowledge is dangerous, where is the man who has so much as to be out of danger?

(T.H. Huxley, 1895)

The testing temperature is rising. States are turning up the heat on schools to improve student performance with more and higher-stakes tests. Stoked by the 2001 No Child Left Behind legislation, which calls for annual testing in every school in grades 3 through 8 to induce adequate yearly progress, policymakers believe they are pushing all students toward proficiency by 2012. In this environment, school leaders face a major dilemma: The high-stakes tests that are used as the major evidence of their effectiveness are, at best, only moderately useful in providing both leaders and their teachers with the instructional guidance needed to improve their school's performance on those same high-stakes tests. As one principal framed the problem, "It is hard to go from the end of one year to the end of the next year looking at an individual child's achievement unless you do something in between... because otherwise how do you assess if what you are doing is working?" State tests, while they serve important purposes, lack the fine-grained and timely feedback to inform instructional decision-making. Relying on high-stakes test results for instructional guidance is like trying to get to the Empire State Building with a map of the United States.

To be useful to teachers and school leaders, test data must provide more than just a destination. Student performance results must also provide guidance that informs educators that they are moving in the right direction, while providing interactive and recursive feedback for mid-course adjustments. In order for student performance data to be useful to teachers and school leaders, and to make it worthwhile for them to make the extensive efforts necessary to learn to interpret and act upon what they learn, data feedback systems must rely on multiple sources of data collected and analyzed at regular intervals.

This report is about building better roadmaps for teachers and school leaders in order to guide their instructional decision-making. The data required for more precise decision-making come from systematically exploiting a variety of student performance data at both the individual classroom and school levels. Rather than just relying on one individual test to provide guidance, innovative school leaders are building more comprehensive systems of assessments that provide better interim information from multiple perspectives. Through more sophisticated data systems, teachers and school leaders can foster a more inquiryoriented approach that involves ongoing and sustained investigations into the kinds of teaching that produce more powerful student learning. In this report, we show how innovative teachers and school leaders are creatively using their data to help guide their strategic decisions. Through their examples, we develop and describe a theory of what a system of school data use might look like.

\section{Organization of the Report}

When we talk about data in this report, we are referring specifically to student performance data in a variety of forms. In our experience, school leaders typically think of external test data when they describe the data that they use. Teachers typically have a more expansive definition of data. When we asked teachers about the kinds of data that they collected and used to inform themselves about current student knowledge and skills, they described a rich variety of sources and techniques to monitor their students' growth, and we have this broader notion in mind. We include in our definition of student performance data a variety of forms that are commonly 
accumulated in schools, including chapter tests, portfolios, reading and writing journals, running records, conference logs, and student grades. When these and other assessments are used to adapt teaching to meet student needs, they are typically referred to as formative assessments (Black \& William, 1998). A common characteristic of formative assessments is that they are used to provide teachers with feedback on individual students. We are interested in expanding the notion of formative assessments to include feedback not only at the individual level, but also across different levels of the school organization. It is the more systematic and school-wide use of both external and formative assessment data that we incorporate into a system of school data use. While we saw evidence of systematic ways to compile and analyze data and turn them into information that could be used to provide guidance for both instructional and organizational decision-making, we saw substantial room to make such practices more widespread and rigorous both within classrooms and across the school.

In this report, we seek to develop a framework to help education leaders develop more robust systems for collecting, synthesizing, and analyzing student performance data in a variety of forms in order to improve teaching and learning. We first describe the three primary sources of student performance data used in schools: external data, individual teacher assessment data, and school-wide data.

Next, we discuss ways that student performance data were used in the schools in our study. We have organized this section into parts that represent the major categories of data use that we learned about. These included: informing instruction, developing assistance plans for low-performing students, planning professional development, setting goals, motivating faculty and students, visually stating school priorities and goals, and communicating with parents. Across these ways that schools used data, two cross-cutting themes emerged. First, the extent to which these uses of data were regular parts of school life pointed to the depth to which a sense of inquiry had taken root into the culture of the school. Second, leadership instigated virtually all of these acts of data use. We end this section with a discussion of the resources, skills, and commitment necessary to use data well.

We conclude by articulating our framework for how school leaders and teachers might more systematically capitalize on student performance data in order to guide their school-wide strategies as well as provide regular feedback to teachers to inform them about the effectiveness of their instructional strategies. Our framework integrates the three sources of data (external, school-wide, and individual teacher) to more systematically stretch over their major uses (informing instruction, professional development, setting goals and targets). We contend that school-wide assessments in particular are an under-utilized and potentially powerful means for using student performance data to leverage instructional improvement. Underlying our framework is the assertion that systematic examination of student performance data is a potent mechanism to develop a culture of systematic inquiry into the relationship between the instructional practices of teachers and the learning of their students. To give the reader concrete and vivid examples of what strong data use looks like, we have interspersed vignettes of each of the schools in the study throughout this report. To protect their confidentiality, we use pseudonyms for the five schools upon which this study is based. 


\section{Data for this Study}

This study was conducted as part of the Consortium for Policy Research in Education's (CPRE) national evaluation of the America's Choice comprehensive school reform design. Since 1998, CPRE has been documenting a variety of aspects of the implementation of America's Choice and assessing the impacts of the design on student learning. In this study, we use schools that are implementing America's Choice as the sources of our data. We collected our data for this study in two ways. First, we conducted a series of site visits and interviews with faculty from a set of five America's Choice schools that were nominated as innovatively using data for instructional improvement. Second, we conducted a survey with a random sample of school principals who were implementing the America's Choice design. Below, we describe our data sources in greater detail.

\section{Site Visits}

The sample for this study is a small set of schools that were identified by America's Choice cluster leaders ${ }^{1}$ as innovative users of data. In December 2001, cluster leaders were asked to nominate schools within their cluster that they felt were using data in particularly innovative and effective ways. Nine schools were nominated. All of the nominees were schools that had been participating in America's Choice for several years as cluster leaders seemed to feel that deep examination of data was a relatively advanced activity for schools and that

1. Within America's Choice, cluster leaders are responsible for overseeing the implementation of the design in a group of 6-12 schools. Cluster leaders are highly trained and experienced educators, well-versed in the day-to-day challenges and rewards of school leaders and teachers, and thus have particular knowledge of a set of schools as well as a perspective on school improvement. only schools deeply engaged in reform would be making sophisticated use of data. From the nine schools, we purposefully selected five, geographically clustered to reduce travel.

Data were collected from each school in two phases. First, using structured protocols, principals were interviewed via telephone about the different ways that data were used in their schools. The analysis of these interviews helped us to develop a basic understanding of the often complex data systems that existed in each site. This first round of analysis helped us to identify themes for deeper investigation and informed the refinement of our protocols.

The second phase involved two-day site visits to each school. During the site visits, we interviewed the principal and assistant principal, at least one other member of the school's leadership team, and at least three teachers (two English teachers and one mathematics teacher in the middle schools). Teachers were identified by the principals, and likely represented those who were most sophisticated in their data use. Because the majority of the teachers that we interviewed were literacy teachers, the examples we use tend to focus more on reading and writing, and less on mathematics and other subjects. During each site visit, we also examined and collected relevant artifacts including school improvement plans, data organization and analysis methods, professional development plans, etc. We also visited many classrooms to examine the data systems developed by individual teachers. Interviews were, in many cases, lengthy because they involved the explanation and discussion of fairly elaborate data systems. Where needed, we conducted follow-up telephone interviews for clarification.

The schools in which we conducted fieldwork are not a random sample of schools by any stretch of the imagination. 
They are outliers in several ways. First, they are all successful implementers of the America's Choice school reform design. We acknowledge that using only America's Choice schools may influence our findings. Second, all of the schools in our sample are low or moderately performing schools ${ }^{2}$ in urban or urban-fringe areas. Third, as America's Choice schools, all are influenced by the America's Choice Planning for Results strategies, which encourage schools to administer, analyze, and plan from the results of the New Standards Reference Examination (NSRE) and to set grade and school performance targets. Further research in a wider array of schools would increase the generalizeability of our findings.

Fourth, our sampling technique within the schools, where we left the nomination of the teachers that we would interview to the principal, probably meant that we interviewed stronger-thanaverage teachers, and certainly those who were advocates of using data and not those who were resisters or felt it was a burden. Thus, the perspective we got was likely from advocates, not antagonists. We do not consider these biases as deficits, given the purpose of the study. Through the design of this study, we specifically sought out the outliers, the cutting edge. We particularly wanted to know about innovative uses of data, not model ones. This is a theory-building study, not a theory-testing study. It is up to ourselves and other researchers to test the conclusions of this study in another sample of schools.

\section{Survey Respondents}

An additional data source for this study was a survey conducted in May 2002 of a random sample of schools completing their first year of America's

2. In terms of absolute performance, although most have improved performance dramatically since adopting the America's Choice design.
Choice. We sent surveys to 68 school principals and asked them to complete the instrument with their school leadership team, a small group of school leaders that is part of the design of the America's Choice reform. Sixty-one leadership teams returned the survey for a response rate of $90 \%$. In the survey, we collected data for several aspects of the America's Choice evaluation; one part was designed to learn about school leaders' uses of different types of student performance data and their perceptions of the utility of different types of student performance data. The schools in which we conducted qualitative fieldwork did not complete the survey for two reasons. First, they were from previous cohorts of America's Choice schools, and second, because the qualitative sample was only five schools, we could not compare their responses to those of a broader cross-section of schools. We used this data as a complement to our interviews to get a broader picture of how school leaders thought about data.

\section{Data Analysis}

All interviews were tape recorded and then transcribed. After an initial reading of the resulting transcripts, we developed a set of codes and coded the data using NVivo, a qualitative software analysis program. Through iterative discussions, the organization of this report began to emerge and we used the coded data to test and refine the final hypotheses. The survey data were analyzed using SPSS statistical software. Simple frequencies, descriptive plots, and chi-square tests of difference were used to explore patterns within the survey results. 


\section{Sources of Student Performance Data}

Knowledge is of two kinds. We know a subject ourselves or we know where we can find information upon it. (Samuel Johnson, 1775)

The schools that we studied drew their data from three primary sources. Most formally prevalent were external data from the state and district. School leaders went to great lengths to process and decompose external test data and glean guidance from these measures. In classrooms, individual teachers fashioned creative and highly customized assessment systems to inform their practice. A few of the schools in our sample were starting to experiment with systematic school-wide assessments that were used to provide interim feedback on progress toward school and grade-level goals.

\section{External Assessment Data}

External data, in the form of state and district test results, were the most systematically mined data source by our sample of schools. The first and foremost external data source was the state test. In New York, the state tests in grades 4, 8, and 11 . In Florida, the state tests in grades 3-10 in reading and mathematics, and in grades 4,8 , and 10 in writing. The two states in our study, New York with the New York State Test, and Florida with the Florida Comprehensive Assessment Test, are considered particularly high-accountability states because of the stakes for schools (vouchers in Florida and reconstitution/ takeover in New York) and students (promotion and high school graduation). Because of these relatively taut accountability policies, school activities in these states are of particular interest as they are likely to be indicative of school response in this era of increased accountability.
In both states, districts commonly supplement the state test with other assessments. In New York, in the socalled "off-grades" (those grades not tested by the state), districts use other measures, like the SAT- 9 or TerraNova. In Florida, districts may use early grade (pre-third) assessments and other tests administered in the fall to supplement the state test. Additionally, all America's Choice schools are asked to administer the NSRE each fall to fourth and eighth graders and to use the results formatively in order to set grade, school, and even individual targets as well as for strategic planning and professional development.

The teachers and administrators in our sample felt that the state test provided some useful, but limited information. Many felt that the state test lacked adequate details to provide much guidance. One Florida principal, for example, explained, "We spent hours and hours...crunching the numbers and we came up with these plans. And from these plans we would say things like, 'We are going to focus on the main idea'...that really didn't mean anything. The test just didn't provide us with enough detailed information." Others complained that the test results were not timely enough. "I wish we had the results earlier," said one New York administrator. "If I had them before they came in the door, we wouldn't be losing time."

The schools in our sample used external assessments in a variety of ways. Some developed elaborate systems to reorganize the individual student results from external tests into ways that were meaningful for them. For example, at one middle school, the vice principal compiled the external data that they received from the state in reading and mathematics over the past two years, along with lexile reading scores, into lists organized by classrooms so that each teacher could see the performance history of their incoming students. Further, students who 


\section{King Elementary School}

King Elementary School in upstate New York is a large K-5 school with approximately 630 students. King Elementary is housed in a large institutional-looking building. Built in the 1970s, the building now sits across from tracts of single-family, low-income housing. King is a bilingual school and has a large bilingual population of students, many from Puerto Rico and the Dominican Republic.

King has a rich assessment environment on many levels. Like many America's Choice schools, running records are interwoven into the fabric of the school year. Teachers report assessing their students every 2-4 weeks, depending on level and need. But the literacy coach makes more sophisticated use of running record data than what we saw in other schools. Four times a year, the coach collects the reading levels of all students from each teacher and produces graphs for each classroom showing each student's reading level at each point in time contrasted to the end-ofthe-year standard and the expected level to be on track with that standard. Any student who is below the expected level is considered "at risk" of not meeting the standard and an academic intervention plan is designed for them. Training for teachers is focused on using this and other assessments to identify where that student is and to match this knowledge with a specific strategy to increase the student's reading level. As an example, the literacy coach explained, "We found out that some of our readers were just calling off the words - you wouldn't call it reading - but with no comprehension. So we had workshops for teachers that supported comprehension strategies, book talks, the text structure, and reading fluency...so the strategies were across the board."

The school's use of state test data is evolving in interesting ways, too. The school's vice principal started using state test data to set school and grade-level targets about two years ago. The leadership team started by taking the previous year's results and setting goals based upon projected improvements. But they realized that this approach was artificial. According to the school's vice principal:

The targets should come from the teachers. Grade-level targets shouldn't be dictated by the school improvement team. And that's kind of what we were struggling with and it didn't make sense to me until this past summer where I realized that before we get grade targets, I need to talk to teachers about their classrooms and if I am talking to teachers about their classrooms, they need to talk to me about kids. And once we set targets for kids, then I am able to give you grade targets.

So, in 2002, the vice principal worked with individual teachers to set targets for individual children and then aggregated those up to produce grade and school-level targets.

Beyond these school-level uses, the teachers we interviewed at King described rich and varied assessment tools in their classrooms. Writing assessments that teachers described including sourcebooks, portfolios, and conference logs. Reading assessments included reading journals and guided reading observations. Mathematics assessments included chapter tests, portfolios, and math journals. 
scored at or below standard on the state's test were listed on large posters in the principal's conference room, along with the students' grade point averages for each quarter.

In another elementary school, at the beginning of each year, the principal prepared a folder for each teacher that included data from the state test - the NSRE (in fourth grade) - as well as within-school data. Using these data, the principal estimated each student's level on a four-point scale that approximated the state test levels and identified those children that were near proficiency.

Overall, based on our fieldwork, the teachers and administrators in the schools in which we conducted fieldwork found the state test data either moderately or minimally useful. A few of the teachers we talked to had no use for the state test at all. "Honestly, I don't use them," said one second-grade teacher. "I don't think the standardized testing really reflects what a child can do in the classroom." According to another secondgrade teacher, "...the whole teaching to the test is sort of a waste of time because you are not really teaching them how to learn. You are just teaching them how to take a test."

Teachers tended to feel that the results simply confirmed the impressions that they had developed by working closely with the children. As one sixth-grade mathematics teacher said, "I usually look at the results and think, 'I could have told you that one was going to fail that area."' But she did find the test results to be useful in providing a broader perspective. "If this group is having a problem with something, then maybe I didn't hit it hard enough. It makes me more aware of what I really have to check for when the next group comes in. So it is moderately useful," she said.
Some teachers felt the external test gave them a starting point. "I generally use it in my classroom for starting off," said one sixth-grade teacher. "The data won't help you identify particular strategies," explained a seventh-grade teacher in another school, "but it will help you to get a heads-up on who you should start looking at a little more carefully." A fourth-grade teacher said:

I want them to walk in and be able to do well on the test, but I keep in mind that

just because they scored this doesn't mean that it's a whole indication on how my child is as a reader and writer and how they do themselves. I have to look at a little bit of everything.

Our survey results indicate that these views are shared in a broader sample of schools. On our survey of school leaders, we also asked several questions about the usefulness of external test data for teachers and school leaders. The responses to three questions are listed in Figure 1.

Overall, three-quarters of the school leaders reported that they found external test data useful to inform instructional decisions, although the majority of those somewhat agreed, rather than strongly agreed with the statement. Just more than half $(54 \%)$ said that they found external student performance data adequately detailed to inform teachers' instruction. Again, two-thirds of school leaders somewhat agreed, rather than strongly agreed. The survey results also confirmed the broad sense that external test data were not turned around fast enough to inform classroom instruction. Less than half of the respondents (47\%) said that they received their state/district test results in time to inform teachers' classroom instruction. 
Figure 1. School Leaders' Perceptions of the Usefulness of External Test Data

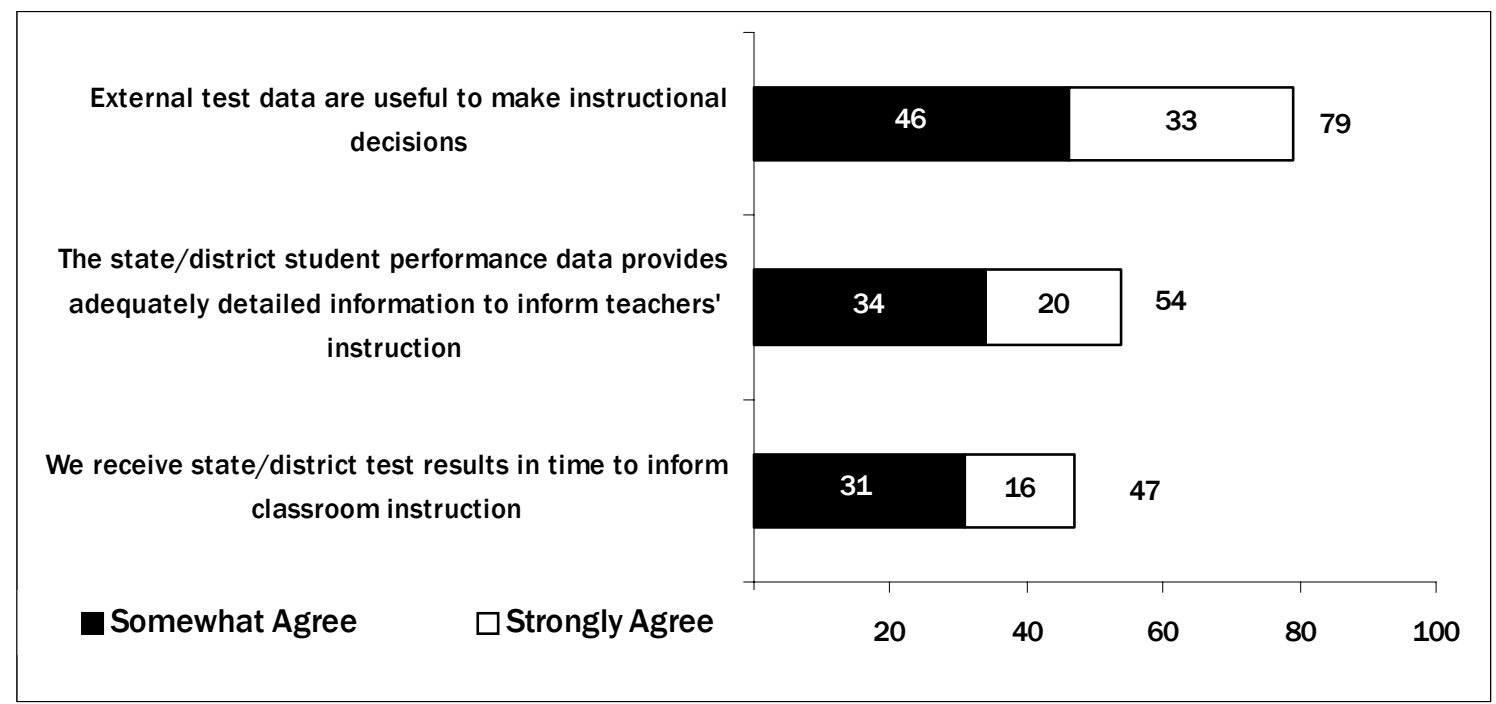

\section{Individual Teacher Assessment Data}

Across the classrooms that we visited and the teachers that we talked to, we heard about a wide array of individual use of assessment data, including chapter tests, portfolios, reading and writing journals, running records, writing notebooks, math journals, and conference logs and other note-taking and documentation techniques of student progress. We consider individual teacher assessments to be assessment data that are used within the classrooms of individual teachers. By this definition, we consider assessment practices that are common to multiple classrooms still to be individual if the results of those assessments are not aggregated and discussed across teachers. Thus, while an assessment tool may be common in classrooms across a school, what can be learned from systematically examining these data are untapped.

There are two types of individual assessments. One group is those that are common, but individually used, across multiple classrooms in a school. As all of the schools in our sample are implementing America's Choice, many of the teachers used similar assessments from class- room to classroom and from school to school. These included running records, writing notebooks, conference logs, source books, and math journals.

The second group of individual assessments is more novel. Just because teachers were all implementing America's Choice did not mean that they did not have the latitude to employ their own inventive methods of student assessment. Teachers were doing many kinds of creative things with student performance data within their classroom domains ideas that they had developed individually or picked up somewhere along their teaching journey. Several teachers described unique ways that they organized their data to enrich their picture of their class in the beginning of the school year as well as throughout. A sixth-grade history teacher, for example, described how she used the data given to her by her principal to get an initial picture of her students.

I take the information and put it on these individual cards for individual kids and I know exactly what their levels are and what their reading scores are... and their class grades. This helps me keep track of who is doing what, where, when, whatever, and also I keep track of if a 
student has repeated and if anybody is ESOL [English for Speakers of Other Languages]. So I know right from the beginning what I have got to do. If I have

this, I don't have to flip through papers and papers and more papers. And for parent conferences, I just pull this out and here is the information right in front of me.

A seventh-grade teacher at the same school explained how she supplemented her reading comprehension assessments using data generated by students. Her interest was in finding out whether her students "[we]re understanding what they read." Initially, she was keeping a record of which page the students were on in their book, however she noticed that some students "just keep reading to get to the end," and they "go through on autopilot." In response to this, she developed a system to help students keep track of their questions as they read and to check for their comprehension:

I give a stack of sticky notes to the kids and, as they finish each chapter, they write down questions, or if they have a question, they write it down, stick in the page, and it sticks out in the book so they can remember that they had a question in this area. And when they write it down, they remember it a lot better than if they haven't written it down and just kept reading. If they have no sticky notes in a chapter, then they should be able to tell me what the chapter is about.

This system allows for a more indepth understanding of students' reading comprehension. It also enabled the teacher to keep a record of how her students were progressing through the year and the record-keeping is shared between the teacher and students.

Rather than thinking of assessment as the end point of an educational experience, some teachers essentially blended their assessments within their instruction. In this way of thinking, assessment is part of the process of learning, an "occasion for learning" rather than the end product of learning (Wolf \& Reardon, 1993). One example of this came from a fourth-grade teacher who described much of her teaching as based upon immediate, almost instinctual, responses. The teacher explained:

I do a lot of teaching on the spot, mixed with my assessments. Like if I see that they're having trouble with something when I'm conferencing with them one-onone, I'll do a little quick mini-lesson. I mean none of this is written in my plans because I don't know what's gonna come up.

While we were interested in the data teachers used in the classroom, it was beyond the scope of this study to systematically catalogue and explore the intricate ways that teachers used data in their classrooms. Thus, we are in no position to comment on important questions of the reliability and validity of these individual assessments and whether teachers interpreted and acted upon them appropriately. But, what we can glean from teachers' discussions of their use of data is this: Teachers in these schools are willing to create (in some cases, very sophisticated) methods of data collection within their classrooms that rely on a set of activities, conferences, or other prescribed ways of accounting for student learning. The data collection is aimed at capturing students' learning and understanding. It is then used to guide teaching practice in at least two ways: It allows teachers to decide if they want to offer individual or group attention, and it allows them to assess the effectiveness of their chosen approaches. Familiarity with their data collection systems permits teachers' decisions to be both dynamic and recursive; that is, they can move back and forth between their data systems on the individual level, on the class level, and their personal interactions with their students not only to get a better picture of how students comprehend, but how students are responding to strategies applied by their teacher. 


\section{School-wide Assessment Data}

School-wide assessments were the most powerful, but least frequently used, form of assessment in the schools in our sample. We define school-wide assessments as assessments that are not only administered systematically across groups of students within a school, but whose results are aggregated and systematically analyzed for patterns that are then used to guide school and individual teacher decision-making. The same school-wide assessment needn't be used with all students in a school, and are more likely to be used across a single grade level or content area. In the schools that we visited, there were four primary examples of school-wide assessments.

Each used different types of data, but all had the common purpose of broader aggregation and systematic guidance. The first example of school-wide assessments was the administration, collection, and analysis of running records, which were used to capture students' reading levels. As a central part of the America's Choice design, running records were used in all of the elementary schools that we visited, although the degree to which the results were systematically utilized differed across the sample of schools. Some of the school leaders in our sample were more methodical in their collection, analysis, and presentation of running records, and tended to take more specified actions based upon the results. In one elementary school, running records data were collected from each teacher at the end of each quarter. The results were then aggregated, and the school leaders and each classroom teacher examined the results for patterns that could provide instructional guidance.

From what we observed, the best example of an existing interim assessment is running reading records, which is a system of assessing reading fluency (but not comprehension) along a developmental continuum. The features of running reading records that make them exemplary examples of school-wide assessments are: (1) they are manageable within the classroom context (although they require teachers to develop classroom routines that free them to do individualized assessments); (2) they provide information that can be translated into insight into the impediments that stand in the way of reading fluency, and thus provide teachers with information from which they can craft instruction with strategies targeted at either individual students, small groups, or entire classes, as required; (3) they can be done frequently so that teachers can adjust their instructional strategies as student needs change; (4) they can be consistently applied across classrooms; (5) they can be recorded on a developmental scale across grade levels; and (6) they can be aggregated to show patterns across classrooms and grade levels, which can be used for organizational decision-making.

The second example of school-wide assessments were theme tests that came from texts or that were part of a curriculum series used across a grade or content area in a school. These theme tests tended to be used at a grade level in elementary school or at a grade level within a subject area in middle school. Teachers administered these theme tests across a group of students and quickly scored and analyzed the results. These theme tests offered the opportunity to assess all students in a particular skill or content area and use the resulting evidence to draw conclusions about the effects of the instruction of either individual teachers or groups of teachers.

Running records or theme tests are examples of assessment systems constructed outside of the school. A few schools in our sample had more ambitious aspirations. The third example of 
school-wide assessments were those that were developed within a school. Many of these were often in their early stages of development. For example, one of the elementary schools in our study was starting to apply the idea of school-wide assessments to writing. The school's coach explained:

We're looking at it to see if the standards are in place, if the work has the critical elements for the genre study, and if the students have met all of them. And some teachers have created class profiles that show that this child has met all of the critical elements for narrative writing and they've met all of the critical elements for report writing.

The in-house development of assessments had the advantage of helping faculty to examine the relationships between standards, curriculum, and student performance. In one of the middle schools, the principal was starting to get grade-level teachers together to develop assessments that represented the big ideas in that subject area at that grade level. As the principal described the process:

We started by considering a curriculum development model like Understanding by Design (Wiggins \& McTighe, 1998) and we came up with authentic assessments that were tied to a standard, so that when students did the assessment we could see where they were in relation to the standard. So our assessment could be our evidence of where we are getting them to in relation to the standard...I had a group of teachers sit down, let's say I get seventh-grade social studies teachers, and they are teaching world geography, and they say, "Here are the main ideas, here are the essential questions, this is the big stuff we want kids to know." In order for us to assess whether they know this, let's have them do this task, and this is the rubric that goes with it. These are the standards we are addressing, this is really significant. If our kids can do this, and to do that we need to teach them these things, but if they can do this it shows mastery of this, then we know they are meeting these standards.

While this process was an ambitious undertaking, it has the potential of being an extremely powerful development activity. For not only are teachers potentially developing an important intermediate assessment, they are also engaging in a conversation about the essential ideas for them to build their instruction around. Wiggins and McTighe (1998) call this the "backward design process" whereby groups of teachers identify desired results, determine acceptable evidence and forms to compile that evidence, and only then plan learning experiences and instruction.

In two of the schools in which we conducted fieldwork, school leaders had stretched the school-wide assessment concept to begin to reconceptualize the system of grading as an outgrowth of the idea of a school-wide assessment. One of the elementary school principals described the evolution of his vision of how grades could represent uniform judgments based on common assessments that would produce meaningful data:
A few years ago, we began looking at the students exiting our school in fifth grade and going on to middle school and they weren't too successful. So we met with the teachers to discuss grading for social studies, science, and math. So it will be across the board, so that everybody has criteria for the grades that they give, and so how to think about creating common criteria for the grades that they give.

Because grades have traditionally been so subjective, they lack the validity to use them to reach any conclusion about student performance beyond an individual classroom. As one of the middle school principals described this problem, 
"Our grades are not meaningful because the judgments that produce the grades are not meaningful. The argument against using grades is subjectivity, because grades don't really mean the same thing from teacher to teacher." As this principal so succinctly points out, it is the variably reliable and valid assessments that are aggregated into grades that are the source of the problem with grades as a commonly understood school-wide indicator.

So this principal had begun the journey with his faculty to develop common assessments that would contribute toward grades. In this way, grades would be developed from school-wide assessments that were constructed as indicators of students meeting standards for that grade level. As he told us:

So how do you make grades meaningful? It is the type of assessments that those grades come from. What are the standards we are teaching? What are we expecting kids to know and understand? Then where are they now and what do we need to teach them? So we are starting off with what is the standard and what is the task that we are going to ask them to do and then building what do they have to know to meet the standard so that it is meaningful.

If done well, the standardization of grades across a school can provide uniform meaning for performance. Grades have a huge advantage in that they have a long tradition as an indicator of quality, are very meaningful to both parents and students, and are embedded into the routines of school.

Whether school-wide assessments are developed from "off-the shelf" instruments, created internally, or even connected to the grading system within a school, these shared assessments are particularly powerful because they provide teachers and administrators with common student performance data, ostensibly based on similar curricular coverage, which provide comparative feedback across classrooms. School-wide assessments create invaluable opportunities to bring practice out from behind classroom doors and provide a forum for teachers to discuss and test their ideas about what instructional strategies produce evidence of student learning. By providing interim results and a forum for discussing them, school leaders provide teachers with guidance on how to make mid-year adjustments. The examination of school-wide assessment results will inevitably provide openings to engage in the powerful discussions of what students are expected to know at different stages of the school year, and what would provide evidence of their mastery. By doing this, students get practice on the elements of the standards they are striving to meet and teachers can refine their practice based upon feedback on students' abilities to perform to standard.

\section{Perceptions of the Utility of Different Data Sources}

School leaders had differing perceptions of the utility of these three different sources of data. On our spring 2002 survey, we asked school leaders about the usefulness of different assessment types. The assessment types we asked about included both those external to the school and those produced and analyzed within the school. We had not, at the time of the survey, distinguished between schoolwide and individual assessments. Our survey results indicated that school leaders overall felt that both external and internal data were useful, but that internal data were of greater value for providing instructional guidance. On our spring 2002 survey, we asked school leadership teams to assess different types of assessments for providing feedback to teachers about their students so that they can design instructional strategies in response. Figure 2 shows the results of the perceived utility of different kinds of assessment data. Each bar in the figure is 


\section{Figure 2. Perceived Utility of Different Kinds of Assessment Data}

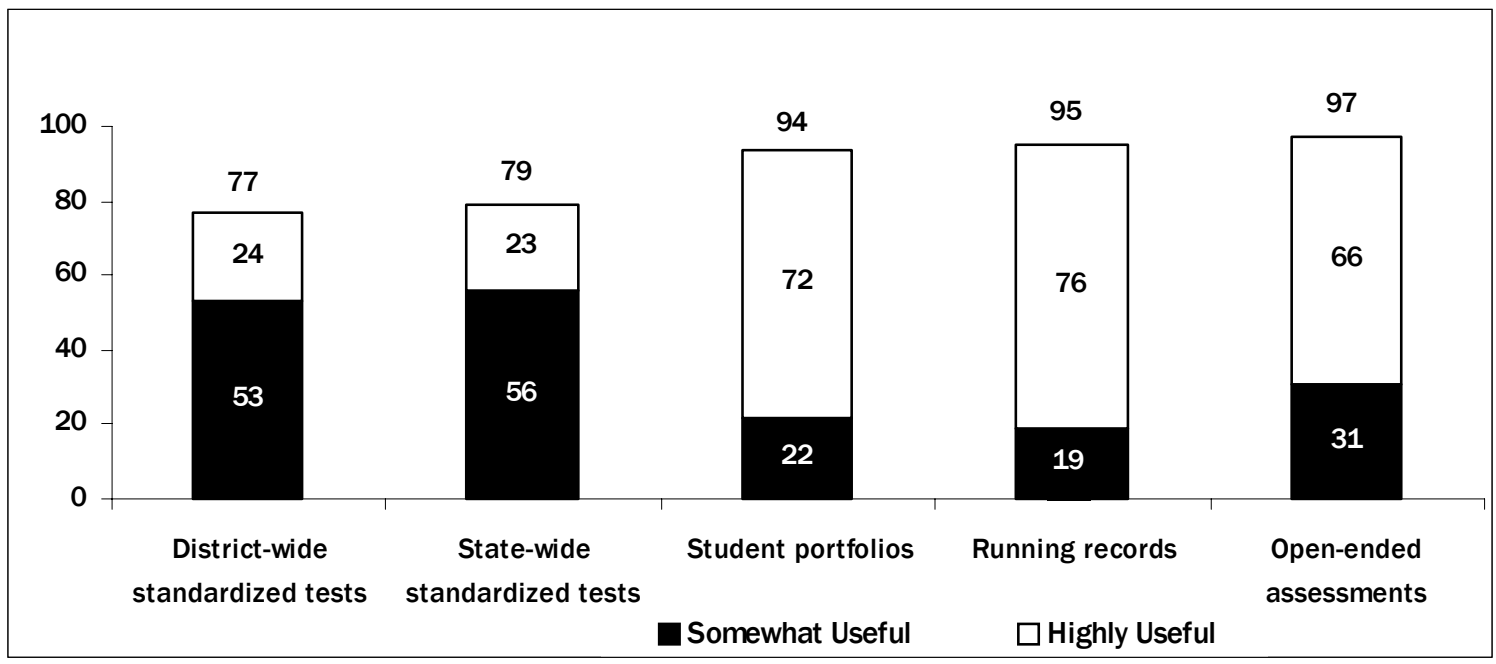

broken into two parts: the percentage of respondents who said that assessment type was highly useful and the percentage that said the assessment type was very useful. The sum of these two percentages is shown at the top of each bar.

Two things are readily apparent from Figure 2. First, assessments that are developed inside of the school (student portfolios, running records, open-ended writing assessments) are considered more useful than external assessments (state and district standardized tests). Second, and even more striking, is the proportion of school leadership teams that find these types of assessments highly useful. While less than a quarter of school leaders find state and district test results highly useful to inform teachers about their students so that they can design instructional strategies in response, about three-quarters of respondents thought that the internal assessments (student portfolios, running records, open-ended writing assessments) were highly useful.

Reasons for these perceived differences in utility had to do with timing, detail, and training. Slightly more than half $(53 \%)$ of our survey respondents said that they did not receive their state/ district test results back in time to inform classroom instruction. Just under half (47\%) reported that state/district test data were inadequately detailed to inform teachers' instructional strategies. Inadequate training at the school level was also a concern. Thirty-nine percent of respondents felt that administrators did not have adequate training to analyze external data effectively. Fifty-nine percent felt that teachers lacked adequate training to analyze external data effectively.

\section{Uses of Student Performance Data}

Where's the wisdom we have lost in knowledge? Where is the knowledge we have lost in information? (T.S. Eliot, 1934)

Students produce a mountain of work in school each year, but only a fraction of those data are mined for instructional guidance. In this section, we describe the major ways that the teachers and administrators in our sample described how they were using student performance data. We have identified seven major ways in which the teachers and administrators in our sample explained how they used student performance data for instructional or organizational improvement. First and foremost, they used student performance data to inform instruction. Second, they used data 


\section{Parker Middle School}

The work of Parker Middle School is literally under construction. In 2001-2002, the year we did our fieldwork, Parker was housed in a host of temporary trailers while its venerable brick building, which had housed the school since 1927, underwent renovations. From 1991 until 2000, Parker had been a magnet school for the arts. In 2000-2001, Parker became a neighborhood school, serving approximately 500 students, and adopted America's Choice. In the construction year, school enrollment was temporarily down to approximately 470 students in grades $6-8$. About $59 \%$ of the students in the school received free or reduced-price lunch, 54\% were African American, and 39\% were White. Like almost all the school leaders we talked to, Parker's leadership felt that their work using data was under construction, too.

Trailer number one housed the principal, vice principal, and the school's secretaries. A small conference room to the left of the principal's office was plastered with large $3^{\prime} \times 5^{\prime}$ posters that depict the students who scored at the lowest level on the previous year's state test. Each poster contained the reading and mathematics state test results for 2000 and 2001, students' lexile reading levels for each quarter of the school year, the number of books they had read through that quarter (the district's goal was 25 books), and comments for each quarter. Updating the posters quarterly, the principal and vice principal used the charts to monitor student progress, have conferences with teachers about how to move students forward, and to have conferences with students and celebrations for students. The school's vice principal said:

We've got to get students to realize it is okay to be smart, okay to do their homework. It's okay to excel. And we do everything we can to reward children who have reached their goals. We have celebrations, we recognize over the PA [public address system], we recognize them at PTA [Parent Teacher Association] meetings.

Further, Parker's administration has developed a system for tracking students every quarter. They have built data forms that they provide to every teacher. The data include the same information on the posters, but for all students not just those at risk. Teachers in the school get the same data for all their students. One of the school's primary goals, as stated in its school improvement plan, is to bring every child up to the state standard. Data-driven accountability extends to teachers as well as students. Parker's administrators use data to inform them about teacher, as well as student, performance.

The teachers we talked to at Parker found the data provided by administrators to be helpful. Most used the data provided by administrators to target low-performing students for extra attention. Some thought the data could be more specific. "I wish we could break it down into more specific skills," said one first-year teacher. Further, teachers had their own individualized strategies to assess student performance. For example, one teacher told us how she put data on each of her students on a separate index card, including state test scores, and reading scores from a computerized reading assessment, and used these data to inform students and parents about both progress and areas needing further work. She said, "By doing that, I can show them their improvement and a lot of times these kids' self-esteem is real low, because they think they are stupid and all of that. So when they see themselves progressing, I think that is helping." 
specifically to identify low-performing students and inform assistance plans for these students. Third, they used data to plan professional development. Fourth, they used data to set targets and goals. Fifth, they used data to celebrate both faculty and student accomplishments. Sixth, they used data as a visual means of reinforcing school priorities and focus. Seventh, data were used as supporting evidence in conversations with parents about students. While we have separated these into seven uses of student performance data, we recognize that these items are not overlapping in some ways and that this list is not comprehensive.

As we identified these seven uses of data, two cross-cutting themes emerged, which will also be discussed in this section. The first cross-cutting theme, which underlays the more systematic use of these data strategies, was the development of a system of sustained inquiry into the meaning and implications of the school's student performance results. The second theme was the role of leadership in fostering all of these uses. This section of the report will conclude with a discussion of these two cross-cutting themes.

\section{Informing Instruction}

Standards-based reform could easily reproduce the same instructional problems as traditional curriculum-based instruction. The prevailing way that teachers decide what to teach, and when to teach it, is to use a textbook or curriculum to determine the sequence of instruction, rather than to teach based upon their assessments of students' developmental levels. If teachers stomp through standards in the same way that they have traditionally tramped through textbooks, then they are no more likely to produce greater gains in student learning than they have in the past. One of the things that potentially makes standards-based reform more powerful is the adoption of a more sophisticated way to identify the aspects of standards students have yet to achieve, and to equip teachers with the strategies to help students master the standards. In this report, we focus on the role that data analysis can play in identifying student skills relative to the standards. We focus less on the strategies teachers need in order to address student deficiencies and the professional development approaches required to effectively provide teachers with these strategies.

Virtually everybody agrees that student performance data can provide important insights to guide classroom instruction. On CPRE's survey of school leaders, $84 \%$ strongly agreed and 16\% somewhat agreed that student performance data are an important source to inform classroom instruction. It is exactly because of the insight into instructional strategies that assessment data are perceived to be useful. Black and Wiliam (1998) use the metaphor of how formative classroom assessments can shine light inside of the black box between educational inputs (school and instructional resources) and outputs (high-stakes test results). Assessment results are formative to the extent that they provide feedback to guide what teachers choose to do to increase student understanding.

In our discussions with teachers and school leaders in the five America's Choice schools, we found that data were used in three major ways to inform the decisions that teachers made about their instruction of students. First, many teachers reported that they used data as the basis for identifying lesson objectives: How they decided what to teach. Second, teachers and administrators told us how student performance data were used to guide their flexible grouping of students for more focused instruction. Driven by the number of students in the class who had not demonstrated mastery of the skill in question, this, in some cases, resulted in small group instruction and, in other cases, individualized instruction. Third, teachers described how they used data to align their lessons with standards. 


\section{Using Student Performance Data to Identify Lesson Objectives}

Teachers who attenuate their lessons to the appropriate developmental level of their students are more likely to provide meaningful instruction. In earlier CPRE research of teachers' implementation of the America's Choice literacy workshops (Supovitz, Poglinco, \& Bach, 2002), we identified several characteristics of effective instructional practice. We found that teachers who regularly analyzed student performance in relation to standards produced developmentally appropriate lessons. Several of the teachers we talked to for this study also utilized this "gap-mapping" technique.

In several cases, teachers described powerful lessons that they developed based upon an analysis of student needs, as represented by weak spots in their documented performance. What follows is an example of how a teacher developed an engaging lesson based upon an analysis of prior student performance. The lesson was intended to impress upon fourth graders the importance of spelling conventions without stifling the larger purpose of communicating ideas:

I went through everyone's folders and I made a list of all their spellings and I made up a story. I asked who would like to read this story. The ones who could read it were the ones who wrote it that way. So I said, "No, wait a second. I don't want you to read it because you're the one that wrote it this way. Let's go on to somebody else." So what I did is I had one of the students read it who very rarely makes any spelling mistakes, who is reading on a sixth-grade level. And she read it exactly the way it was written and everybody laughed hysterically and I said, "Do you see how hard that was? Now let me read it." And I read it exactly the way it was written and they're all laughing. It was actually very humorous. And I said, "Do you think I like to read it like that?" And they said, "Oh, we didn't know that's what it said." I explained to them that I lose comprehension of your writing when I have to sit there and decipher all your spelling but I still want to get across the point that spelling is important. My children really like to write, and my rule of thumb is, don't stop in the middle of your writing to look up the spelling of a word. Don't. But before you hand it in, or before you print out the final copy, you need to go look up those words.

This story exemplifies how teachers can utilize the performance data that students regularly produce in order to develop lessons that are designed to help children understand the purpose of particular conventions, in this case spelling, in the service of the larger communication goals. It is particularly noteworthy that the teacher used prior student work to identify the purpose of the lesson (the importance of spelling) and then to construct the lesson out of the students' work so that they could identify with the material. Rather than providing a decontextualized lesson on spelling, this teacher not only analyzed the student work to develop the lesson, but then used the work as the basis of the lesson in order to help students to connect their past performance to the goal of communication.

In our discussions with teachers about the ways that they used data, one of the oft-emerging themes was the way that teachers examined their student performance data in order to cull ideas about what to teach. For example, one fourth-grade teacher described how she made notes from her conferences with students and used these notes in order to determine the appropriate content for lessons that were designed to address students' skills relative to the standards:

I use a conference record form and it tells me what day I conferenced with them and which of the standards I was looking for that day. Here (pointing to her conference 
form), we were working on the setting and sensory details to describe the setting. If there's a little arrow, that means we need to work on those elements [of the standards]. And then after I get all the data collected, I'll go over it and I'll put down the mini-lessons that we need to work on.

Teachers varied in the frequency that they used this technique of mapping student work to standards and then producing lessons designed to fill the gaps. For some teachers, these kinds of lessons represented special instructional occasions. For others, student performance data were a regular source of lesson guidance. As one teacher told us, "Every single thing that I pretty much teach is because I saw in it in their work, or they said it, or I noticed that that was happening where you know I could keep writing this down for my information but everything that I do is from them."

\section{Using Student Performance Data to Focus Instruction}

It just blows my mind how high they can go if you individualize their instruction. (Fourthgrade teacher)

One of the prime advantages of having more fine-grained information about individual students is the opportunity this creates to target instruction toward particular sub-groups, or even individual students. Several teachers described how they used student performance data to group students together for particular instructional purposes. For example, one third-grade teacher described how she used her students' recent performance data to develop mini-lessons for sub-groups of students:

Based on all of this information I've put together, I noticed that a lot of the kids were missing the main idea of the story, so I started looking for this when I was assessing their reading...[But] not all the kids are going to have the same problem...[so] I will come up with a minilesson for those particular students based on their needs.

A second-grade teacher described how she used her running records for flexibly grouping and regrouping students:

I use running records particularly to start children off at an instructional level. When most of them come to me from first grade, they should come in at a reading level of 17. But most times they come in more at a level of 9 or 10. So I use that to get my groups together. But they are not permanent, they move. Some kids move faster than other kids. So if one is a solid 9 in September, then maybe in October they are at level 15. Then they move from that group into the next group. I work that way.

A few teachers described how they used student performance data to refine both the curriculum and instruction for individual students on an ongoing basis. For example, one fourth-grade teacher told us how conferencing with her students and keeping track of what she learned, helped her to appropriately adjust individual students' reading levels. She told us:

I know where all my kids are reading. I know where [student] is reading. I started him at 34 when I didn't know him and then went to 28 and to 24. What I thought of him and what happened was much different. So that was in the beginning and then just writing down what you know - what he is reading and making sure that I don't need to worry about him because he does everything. He has comprehension, he'll do the book reports. I might need to have more conferences with him, and I make sure to guide him through his work if I think it's too challenging...so conferences really help. 
Targeted instruction was sometimes afforded by the ways that state and district test results are reported back to schools. In the following example, a district provided state test result data back to schools in ways that instruction could be individualized. As the school principal explained:

Teachers get all their students' scores from the [state test]. They come back composited by grade level and they come back individualized, so that you can see basically that a child gets a 1,2, 3, or 4 in everything, vocabulary, comprehension, and then in math concepts and problemsolving. And throughout the district, any child that does not meet standard, get a level 3 on either the reading or the math test, they have to do an academic inservice proposal for the child.

While states can provide data back to schools in ways that encourage more focused instruction, they are in a much weaker position to ensure that teachers have the skills to analyze the data and regulate their instruction accordingly. What was particularly noteworthy about the schools that we visited was the ways in which they capitalized on the data that were available to them and organized them in ways that translated the potential value of the data into enacted instructional actions.

In each of these cases, teachers used data about their students' performance to adjust the scope of their instruction. In some cases, instruction was focused on small groups within a class. In other cases, instruction was individualized. In some cases, the data were structured by external organizations to help teachers make these adjustments, while in other cases, the data were created by individual teachers within their classrooms. But, in all instances, classroom data were used to identify both the what and who of instruction.

\section{Using Student Performance Data to Align Lessons with Standards}

Several teachers explained that they used data as a way to help them keep track of where students are in relation to standards. One fourth-grade teacher, for example, explained how she kept track of the class's progress vis a vis the standards:

I have my own writing file and every time I meet with them I pull out the writing file and I say, "Okay, we were working on this standard, okay. Why don't we come back to the response to literature standard or the report standards. Say you know the last time we worked on reports, this is what we needed to work on. We hadn't gotten here. So that's gonna be our goal for this assignment, we need to get here, and we also need to maintain all the other standards that we have accomplished."

In another school, a fifth-grade teacher used a similar mechanism to track writing progress against the standards, but did so for individual students, rather than for the class as a whole. She showed us her writing log, which contained a series of frequent notes (dated about 5-10 days apart) that commented on the students" narrative writing ("needs work on conventions; has beginning, plot, settings, characters"), memoir ("contains conventions, must work on spelling and add details, does not meet standard"), and organization ("folder a complete mess, is not finishing stories, how to prevent boredom? Never has more than one piece in the 'work in progress' section"). As we were examining the log together, she commented:

[Student] doesn't use enough detail, and [student] and [student] doesn't end their stories, so we need to get a final ending together and close the stories out...endings are a big problem for a lot of these kids. They want to tell more and more and more and they don't want to 
end. So, I use all of the log, more so the writing, to revisit and say, "Look what we've done. This is the progress we have made so far. This is what we still have to do to meet the standards. Now how are we going to do that?"

In each of these cases, teachers used their data systems to keep track of and remind them of where their students were in relation to the standards. As teachers delve into the details of daily lessons, it is easy to lose track of the larger goals of daily instruction. Data systems can be useful ways to document and track progress toward ultimate goals.

\section{Developing Assistance Plans for Low-performing Students}

Access to more sophisticated student performance data allow effective school leaders to better support the diversity of students that are in their charge. First, they can more readily identify those students who are in need of additional assistance and more effectively match students' needs to appropriate responses. Second, more timely data allow them to more closely monitor students' progress.

\section{Identifying Students}

All the schools in our sample mined the previous year's state test results to identify individual students who were not meeting the state standards, and to either place these students in intensive classes or implement other focused strategies to assist them to improve their performance. As one principal explained:

... any child that does not meet standards gets a level 3 on either the reading or the math test, we do an academic in-service proposal for the child. It's almost like a mini IEP [individual education plan]. And basically what that says is you are looking at the child's needs and how you're going to address them. So every teacher takes an in-depth look at her students and how they scored globally before she even does any of this. And then we have to look at the targeted need of how we are going to work with the students. For everything from extendedday programs, to individual volunteer tutors that come in, to students who need to...get inclusion support, school services.

In our visits, we learned about a rich array of strategies that these schools had developed to provide support for at-risk students. Some of these were academic, while others were social or emotional, and others involved parental or guardian involvement. Several of the schools in our sample showed us lists of particular students that they had identified for some sort of additional assistance. Types of assistance varied, and included doubleblock periods of either mathematics and/ or English/language arts, course recovery programs in which students could attend Saturday school in order to make up a class that they failed by gaining mastery of the course's content, before- and afterschool tutoring, or assigning adults to mentor at-risk students.

In several cases, the data on at-risk students became the basis for in-school professional development. For example, based on their performance data patterns, one principal explained:

We would try to identify and address atrisk strategies. We talk with teachers and first have them brainstorm why children appear to be at risk. What are some of the factors that the teacher believes are impacting upon this particular child? Is it emotional factors? Is it maybe a vision or hearing problem? Is it trouble reading? And we try to brainstorm at-risk factors and then try to address them.

Targeting the academic needs of lowperforming students is one way to connect professional development to a school's challenges. 


\section{Monitoring Student Progress}

It is one thing to identify at-risk students and provide them with a differentiated set of opportunities to improve their skills and performance. But how does one know that these strategies are working? Administrators in these schools also used student performance data to monitor both student progress and, by extension, the effectiveness of these strategies.

All of the schools in our sample also used their data to monitor the progress of students whom they had identified earlier. As described in the vignette on Parker Middle School, Parker administrators focused their attention on their atrisk students by developing large posters filled with a variety of data on each identified student, assigning that student to one or multiple special support strategies designed to improve their skills and monitoring student progress quarterly. In this way, they could adjust the approaches they took for students who were not showing improvement. Jackson Middle School developed a similar approach by developing a list of students who were not on track to meet the three school goals of adequate grades, reading 25 books, and low referrals, and assigning those students to a variety of support strategies with frequent monitoring and adjustments. In Roosevelt, King, and Mendel Elementary Schools, running record results were used quarterly to identify students that were falling behind and to design support strategies for those students and assign the students to them.

Embedded within the idea that all students can achieve standards is the promise that all students will have adequate and multiple (if necessary) opportunities to acquire the skills to meet expected performance levels. Better analysis and monitoring of student performance data are integral to any efforts to better serve low-performing students. By using their student performance data to shine light onto the students in the shadows, the schools in our sample were beginning to fulfill the promise of standards-based reform. "Look," said one principal, "these were ones that we had targeted in the beginning and they aren't failing anything. So...we're doing something right."

\section{Planning Professional Development}

Research on effective professional development points to the advantages of staff improvement activities that are embedded within the school and constructed around content to fit the needs of the teachers at that particular school (Kennedy, 1998; Little, 1993; McLaughlin \& Darling-Hammond, 1995). The school leaders in our study were able to utilize their data to craft professional development that used findings from student performance results to guide decisions about staff development. The successful application of data to professional development is a multifaceted challenge. First, one must have a data source that can address questions of interest. Second, one must have the skill to analyze and interpret the data and detect important patterns. Third, one must be able to design professional development to teach teachers the techniques to address the need. To take this full circle, subsequent data would have to be analyzed to determine the effectiveness of the professional development.

The school leaders in our study demonstrated their understanding of this sequence as they explained to us how they used their student performance data to guide professional development in their schools. They used student performance data to plan professional development in two ways. First, they used state and district test data to help them to determine initial topics for professional 
development. Thus, data helped them to define preliminary areas to target their staff development. Second, they used subsequent student performance data to refine their teacher capacity-building strategies throughout the year. In this way, they could make adjustments and refinements to teacher development based upon more recent discoveries about student need and teacher response.

At the broadest level, patterns of student performance on state and district tests can provide insights into areas of need for school and grade-level faculties. Many schools, and those in our sample were no exception, use their state and district test results to identify topics for initial staff development. As one elementary school principal explained:

If we see in the area of language arts, for example, that we are having trouble in the area of comprehension, then the staff development would be centered on instructional strategies and techniques that teachers can use to deliver a better program to address those areas.

Using end-of-year test results to plan subsequent professional development has some inherent weaknesses. It seems reasonable that patterns of low performance in end-of-year results reflect a combination of the instruction that students received and the particular habits of that cohort of students. Thus, how are school leaders to know if the subsequent group of students has the same set of needs as the prior one? School leaders and teachers expressed their grasp of this wrinkle by pointing out that patterns in the last year's data do not necessarily apply to this year's group (see the section on "Setting Goals and Targets" for a further discussion of this idea).

One particular advantage of using student performance data collected within the current school year is that it is based upon the performance of the students that teachers are presently teaching. Beyond the initially identified areas, several of the leaders in our sample of schools talked about ways in which they were able to refine their professional development strategies based upon subsequent data analyses. The coach at one school, for example, described what happened after her school's leadership team examined their reading data from the first quarter of the year:
What we found out with some of our readers is that they were just calling off the words, you wouldn't call it reading, but with no comprehension. And we [developed] several workshops that supported comprehension strategies. We worked on book talks, text structure; also we had a workshop for struggling students, where we talked about fluency, when children were reading choppy. You know you could use repeatable reading, and we gave the teachers a list of strategies to select from. So the strategies were across the board. You know if they have trouble with short-answer responses, we talked about question/answer relationships - what do you look for to get the answer to the question - what is the question asking for? So, the teachers got all of it and they picked appropriate strategies.

In this school, leaders developed a series of professional development experiences for teachers based upon current data.

A few of the school leaders in our sample had a particularly organic view of constructing teacher professional development from their analyses of their data. Rather than view professional development as the outgrowth of data analysis, they incorporated the data analysis process into the professional development experience. A few of the school leaders thought about professional development as both the process of identifying problems as well as construct- 
ing and delivering strategies to address those problems. For example, one principal described what she called an assessment workshop that they conducted at each grade level:

We asked the teachers before the workshop to bring their data. From that we identified together the names of the children at risk and possible reasons for them being at risk. And then we charted the reasons on a big chart of paper and looked for commonalities. We then brainstormed solutions, possible solutions, together.

Similarly, another principal described the process by which they used data to construct a professional development session in her school: "We took a piece of student work and put it up on the overhead and analyzed it together, element by element." At the next session, the principal explained, teachers looked at the student work from their own classes and, working in grade-level teams, began analyzing their own students' work. Teachers were then asked to translate what they saw into one or a series of mini-lessons, according to the particular deficit(s) that they saw in their class. In both of these cases, the school's student performance data formed the basis for a collaborative investigation into the meaning of the results and then served as a way to mutually construct strategies to address these identified problems. The process of inquiring into the meaning of student performance data itself became part of the professional development experience.

\section{Setting Goals and Targets}

The bottom line is the data. When I go to be evaluated by the superintendent, he doesn't want to know how many nice things I have done for my staff. He wants to know how I have increased student achievement. And I let [the faculty] know that these are my goals as a principal and my goals for the school. (Elementary School Principal)
Student performance data provide schools with clear measures of improvement and progress. Student performance data are a particularly useful mechanism for setting goals for future performance. The schools in our sample had distinct and interesting ways of thinking about how to use their data to set goals and targets for improvement. In this section, we talk about two distinct ways that were used in one or more of the schools in our sample to set goals for improving student performance. First, school leaders used their student performance data to set ambitious annual improvement goals. Second, they used their data to set intermediary goals that showed progress toward their annual goals. In this way, their longer-term goals became more immediate and could be tied to instructional approaches that could be adjusted.

The Planning for Results component of America's Choice provides a good model for schools to set global goals and targets. Through Planning for Results, America's Choice helps schools to set school, grade, and individual student goals based on analysis of the NSRE, which is administered in the fall in grades 4, 8, and 10 as part of the design of America's Choice. Although schools find the NSRE expensive, and Harcourt has had trouble providing results to schools efficiently, school leaders appreciate the quality of the data that are provided and the details on dimensions of student performance that are provided in English/language arts and mathematics. As one school leader said, "The reference exam is fantastic for breaking [performance] down by each child and each level. This gives us a lot of individualized data to set targets." These elements of the America's Choice design facilitated schools' goal setting. 


\section{Mendel Elementary School}

Data analysis is in the genes of the Mendel Elementary School in New York State. The school is named after a well-known scientist, one of the local university's founding faculty members. The school is small, with 350 students in grades pre-K-5 and shares a building with a city-wide, inquiry-based learning magnet school. Approximately $35 \%$ of the students are Hispanic, 50\% African American, and 10\% White/Asian. Thirty-five percent of the students are English Language Learners. The school adopted America's Choice in 1998 and since then it has demonstrated outstanding improvement. The percent of students meeting or exceeding standard on New York State's English/language arts test went from $11 \%$ to $37 \%$ to $57 \%$. The school's leaders use external test data to set goals, guide instructional emphasis, channel professional development, and focus celebrations.

The school's principal uses standardized test data to set goals for the school each year. "I took where we had to be in 2003 and divided it into equal portions," the principal explained. "It may not be reasonable, but it is an overarching goal of where we need to go." Each August, the school staff examines the district-wide Stanford-9 and the NSRE results for third graders and examines how close students are to moving up on the four-point state fourth-grade test. They then set individual targets for each student. The principal finds the NSRE and the item analysis provided by the district for third graders particularly useful because of the fine-grained guidance they provide.

But, the school staff recognize that these data, although good information, do not provide enough guidance. "It is hard to go from the end of one year to the end of the next year looking at an individual child's achievement unless you do something in between... because otherwise how do you assess if what you are doing is working?" the principal asked. Therefore, the faculty uses multiple other instruments to provide guidance along the way. In reading, these include running records to formally assess fluency and word-attack skills at least four times a year and often more frequently for students in the early grades and students at risk, as well as frequent story retelling to assess reading comprehension. In writing, teachers use a portfolio system that has evolved in the district that contains rubrics linked to elements of the standards. In mathematics, teachers use portfolios and theme tests closely linked to the curriculum.

Data are also central to guiding professional development. According to one of the literacy coaches, the leadership team uses data to develop professional development "according to areas of need, where to move students." For example:

If we see in the area of language arts that we are having trouble in the area of comprehension, then the staff development would be centered on instructional strategies and techniques, how teachers can deliver a better program to address those areas. And then there will also be some modeling by the instructional support teachers - going into the classrooms and modeling the same strategies, and watching the teachers teach and critiquing them on a professional level.

The school does not hesitate to celebrate its success. According to the principal, students celebrate as soon as they take the test: "I tell them that the only person that is going to know if they did the best that you can do is you and your teachers, because she knows you everyday." When the results come in, the principal puts thank-you notes in each teacher's box and acknowledges them in end-of-year celebrations. Judging from the school's recent success, the principal must have been doing a lot of letter writing. 
Setting Ambitious Annual Improvement Goals

All of the schools in our study, as do most schools, used their state test results from the previous year to set school goals for current-year performance. However, these goals are fairly arbitrary. For example, one elementary school leader described how she set her school goals based upon state expectations:

We look at where we need to be, say by the end of 2003, when we need to have a certain percentage of kids meeting standards. So we looked at where we were two years ago and broke it into thirds. Then we look at that every year as our goal.

Many school leaders also struggle with the legitimacy of setting school goals by looking at the school performance data from previous years. What is a reasonable and legitimate goal to set? Just because a school had $X \%$ of the fourth graders meet the state's standard one year, does that mean a greater percentage should meet the state test the next year? Isn't this too dependent on the particular group of kids at a grade level, particularly in small schools? These kinds of questions trouble both thoughtful school leaders as well as architects of accountability systems that attach rewards and sanctions to changes in school performance over time.

The school leaders in our sample responded to this issue differently. One elementary school principal sought to identify areas of need that were represented by the test results and to turn this into a series of actions that the faculty could take to improve their students' performance. As she explained:

We look more specifically at overall areas of need - ours was in the area of comprehension. If students are getting to the end of third grade and they are still having difficulty with comprehension, then it is not just a problem with those students, it is a problem school-wide. So we set our school-wide targets based upon the third-grade needs. For example, specifically which needs in the area of comprehension do we need to address. And each grade level looks at their curriculum and their standards and which activities need to be emphasized in order to bring up those areas. And then I look even further for when I am reviewing lesson plans, doing teacher observations.

A clear identification of goals helped to organize the school's strategies for improvement.

A vice principal in another school in our study took a very different and inventive tact. He focused on building legitimate school-wide targets by aggregating up from individual student improvement goals. His approach to gradelevel goal setting had evolved substantially over the past several years. In the first year of implementation of America's Choice, his school's leadership team had developed school targets based upon the previous year's test results. As he explained:

In previous years, we were able to set school targets, the school target for the fourth grade - you know so many percentage of kids will pass. And that's as far as we got one year...But in reflecting back when we set those targets, it's wrong right there. Because the targets should come from the teachers, number one. Number two, grade-level targets shouldn't be dictated by the school improvement team. And that's kind of what we were struggling with, and it didn't make sense to me until this past summer where I realized that before I get a grade target, I need to talk to teachers about their classrooms and if I am talking to teachers about their classrooms, they need to talk to me about kids. And once I get targets for kids, then I am able to give you a grade target. So we were going 
backwards. We were going grade attempting to get to the individual and this past summer a little light bulb went off and I said, "It has to start with the individual."

This realization led him to explore more deeply into the question of how to set legitimate goals for student progress using individual students' prior performance data. As he explained:

\section{And that answer, I only will get when I} have time to sit with my teachers to go student by student. Because I know that I have a smart-aleck teacher who says, "Okay, you want me to plan for results, my twos are going to be threes and my ones are going to be twos." You know, ideally that is what we want, but is it real? And if it's not real, then how effective is the exercise and how much will a teacher benefit from using this information?

This led him to have candid conversations with teachers about realistic expectations for each student.

And so she's targeting him to stay at a two, so my discussion with this teacher would be, "Why? How far back is he? Let's look at his running records. What's his writing looking like?" And so we'd be able to have real conversation about why that child is still going to remain a two for this year... So this gives us a way to have a conversation about real kids.

Using this approach, the goals for this school are solidly built upon realistic expectations of student growth.

Enactment of this strategy is still embryonic at this school, and the vice principal has only begun to have these kinds of conversations with teachers. But this approach points to a way that data have helped the leaders at this school explore ways to have conversations with teachers about reasonable expectations for individual student progress, set more meaningful goals for student growth, and helped them to set realistic goals for school progress.

\section{Setting Finer-grained Goals}

Annual goals seem awfully distant for teachers and school leaders. How do they know if they are making progress toward those goals? The natural answer to this question is to break down longer-term goals into a series of more immediate objectives. Several of the schools in our sample decomposed their annual goals into a series of quarterly expectations that served as guidance toward their ultimate targets.

For example, in one elementary school, the interest in using student performance data to set interim goals was driving the school toward developing a set of quarterly targets for reading performance. The school's principal called the system her "BI-LO" reading system. As she described it:

The consensus in research is that children at the end of Kindergarten are reading at level $B$, first grade at level I, second grade $L$, and third grade O. It's called the BILO. With that in mind, we made sheets and kind of categorized the children's reading into different levels. Which children at which levels would be considered at risk? Which children reading at which levels would be acceptable? Which levels are on standard and which levels are exceeding the standard? So we did that in September, but we took it a step further. Our vision was that we took the running record log in which teachers tabulated their readinglevel results in September/October, December/January, March/April, and June and correlated this with the categorization sheet. For September, for example, a child reading at level D might be fine for first grade, but come January, if he is reading still at level $C-D$, he will 
be at risk in January. Each quarter turn of the year, we may add more children in the at-risk category, because we want children to be going toward the benchmark level.

In this school's system, interim goals were as important as ultimate goals. The refinement of the BI-LO system into subgoals for each quarter set clearly articulated targets for student reading performance in each quarter of the year. This gave teachers a sense that they were progressing toward the end-of-year goal.

The use of running record data to set interim targets was a prevalent pattern that we noticed across the three elementary schools in our sample. Another of the elementary schools had set up a similar system. Each quarter, the school's coach collected all the running record data from each teacher and developed graphical representations of the progress of students in each class. Each graph contrasted current student performance not only against the end-of-year expected reading level, but also against the reading level for that month of the year. According to the school's coach:

We break our data down by teacher, by grade level, and we use these data to say, as of February, [this is] where her students should be at. Any of the students that fall below that line, we consider those children to be at risk. And the teachers needed to accommodate them.

Running records are a particularly appropriate assessment model for setting interim goals because they contain welldefined levels of developmental progress that can be used to measure incremental progress.

\section{Making School Improvement Goals Public}

In most schools, student improvement goals are buried deep within the school's improvement plan. If one asks teachers and students in the building what their school's student performance goals are, they would not likely know. Yet, one of the middle schools in our sample took a very public and powerful approach to goal setting and the goals of the school were highly visible throughout the school and were well-understood by teachers and students.

At the beginning of the 2001 school year, the school's leadership decided to focus students and faculty on three clear performance goals: Students achieving no grade less than a $C$, reading 25 books, and having no disciplinary referrals. As one of the school leadership team members explained:

Normally in a school improvement plan, you are going to see a lot of references to the [state] test, to math scores and reading scores, and writing scores. That has been a push for years and years and years. But it means nothing to the children. They don't understand about test scores, they don't see those test scores until the end of the school year. They don't know how they are doing in terms of being on track. So instead of pushing the [state test], we wanted them to succeed in class - by making no grade less than a $C$, and reading 25 books, that is what they are doing, succeeding in their school work. So in a sense, we are addressing those [state test] scores...It just took away the whole burden that was on their backs to do well on the test.

The principal met with students and explained what he wanted from them: The three goals for student performance. And they told him what they wanted: Better lunches, cleaner restrooms, field trips, and dances. And he presented the goals to the faculty and to parents at the open house. The school's assistant principal said:

This was his way of getting the students and school community involved. With school improvement plans in the past, we 
had buy-in from the teachers. The teachers worked very hard to do what they were supposed to do...but we never really included the students. We never really got input from them. We never asked them what was keeping them from being successful in those areas.

This created buy-in from students, teachers, and parents. What students expressed that they wanted - field trips and dances - became the incentives that school leaders used as rewards for achieving their goals.

The leaders of this school were able to make these goals the unifying focus of efforts. They identified three immediate and relevant goals, engaged students and teachers in discussions of these goals, and used these goals as the focal point of improvement efforts. By creating a situation in which all parties had a vested interest, school leaders were able to motivate constituencies to participate in the achievement of these goals.

\section{Celebration for Faculty and Students}

Evidence of improvement is always worthy of a good celebration. Many of the administrators in our sample of schools took the opportunity to celebrate improvements in their students' performance as a way of motivating both students and teachers. By sharing the results of data analyses, school leaders can create a whole-school awareness of both achievements and areas of need. Making these areas explicit allows for celebration and, in this study, we saw schools celebrating in various ways. As one principal explained, data allow her school to see where they are, set goals, and then it gives them something to celebrate once they've achieved their goals.
The same principal celebrates a standardized test twice, once at the completion of the test as a congratulations to the student for doing the best that they could. As she described, "I tell them that the only person that is going to know if they did the best that you can is you and your teachers, because she knows you every day." And there is also a school celebration once the test has been scored and results reported. She stressed the importance of celebrating with both students and teachers.

In one of the middle schools in the study, for example, teachers were asked to assess the reading levels of at-risk students more frequently. As one of the teachers explained:

By doing that, I can show them their improvement and a lot of time these kids' self-esteem is real low...so when they see themselves progressing, I think that is helping. I have had some kids that refused to read, non-readers, and they are really interested in reading now. One little boy wants to be an architect and he is getting every book he can about architecture.

On the individual level, attention to students' progress allows teachers to note and then celebrate significant growth on the part of their students.

Another seventh-grade teacher explained how they use reading logs to direct some of the school's celebrations. "Sometimes there's just a reading log. And then every quarter we have a celebration with those kids who are on track." In this school, the goal is to "to get across to our children... a desire to do better...to get them to realize it is okay to be smart, it's okay to do your homework. It's okay to excel. And we do everything we can to reward children who have reached their goals. We have celebrations; we recognize them over PA, we recognize them at PTA meetings." Celebrations serve an important function in this 


\section{Jackson Middle School}

Jackson Middle School, serving about 1,000 students in grades 6-8 in northern Florida, has found an inventive way to translate data into meaningful goals for students and staff. Rather than focus on test scores, the school emphasizes course grades, reading, and student discipline.

When one walks into the 1960s-style wood-paneled front office at Jackson Middle School, a festive display board to the left demands attention. Under the banner "Celebrate Learning," a series of graphs depict the school's progress toward its three main goals of promotion, reading, and discipline. First, students are expected to make no grade less than a C. Second, all students are expected to read at least 25 books, which is the district's reading goal for all students. Third, students are expected to receive no referrals for discipline problems. As the school's principal explained:

Normally in a school improvement plan you are going to see a lot of references to the (state test). But it means nothing to the children. They don't understand about test scores and they don't see them until the end of the school year. We decided to address promotion, discipline, and reading to make our goals meaningful to students. Instead of pushing on the (state test), we wanted to push them to succeed in their classes. It just took away the whole burden that was on their backs to do well on the test.

The three goals are at the core of Jackson's innovative data use. The school, which is equally divided between White and African American students, has about $58 \%$ of students receiving free or reduced-priced lunch. Each quarter, the school's assistant principal updates a database that contains each student's progress toward each of the three goals, as well as information on safety-net programs that students may be participating in (tutoring, team-up, course recovery, etc.). From this database, the school's leadership team can generate reports that tell which students are meeting the three goals for the quarter (and are eligible to participate in rewards like field trips, dances, and parties) and which students are at risk, and enrolled or not enrolled in safety-net programs. The data also have produced some very provocative insights, such as the fact that many students were failing because they did not "dress out" for gym, and thus failed physical education (P.E.) even though they were passing their academic classes. The vice principal explained:

P.E. is not a requirement for promotion, but it is a required course and it is included in your GPA. Last year, the promotional requirement was a GPA of 1.8. We had a large number of kids who did not make the 1.8 because of P.E.

Collecting these data, particularly course grades, are a chore. The school leadership has done a good job of distributing responsibility for this data collection. The team leaders of grade-level teams are using laptops to maintain the database of performance for students on their team. The team uses their data as the source of conversations.

School administrators also feel that the attention to data provides them with a means to familiarize themselves with the large student population. "I think it has caused me to look at every child," explained the school's vice principal. "I see them out on the breezeway and I don't know one from the other. But, I know every name. I've gone through and I know these names and it is helping me to find a way to reach all the kids." 
school; they are part of an explicit effort to change the nature of students' interactions with school and school work.

\section{A Visual Statement of School Priorities and Focus}

If a single picture is worth a thousand words, then the visual display of student performance data speaks volumes. Some of the most powerful and enduring images of the ways that the schools in our sample used their data come from ways in which they visually presented their data in order to signal their priorities and focus. In some cases, displays were public, intended to signal priorities to students, faculty, and parents. In other cases, the visual representations were used by school administrators as working documents to monitor students and develop strategies with faculty. In still other cases, data were organized and displayed visually in order to gain insight into patterns that would otherwise not be apparent. In this section, we describe different ways that schools visually represented their data and provide examples of the power of visual representations of data.

\section{Trumpeting Goals}

At Jackson Middle School, displays of its data served to trumpet the school goals. Graphical representations of each of the three school goals - students reading 25 books, students getting no grade below a $\mathrm{C}$, and students receiving no disciplinary referrals - were festooned throughout the school. Most prominently, in the entry hall to the school's main office, a display case featured statements of the three school goals (connected to the school improvement plan), and graphical evidence of the school's progress toward meeting each of the goals (see Figures 3 and 4). Each graph showed the school's aggregate quarterly progress over the past two years and was accompanied by a specific statement of the goal (e.g., "the percentage of students in all grades meeting the 25-book reading standard will increase from $30 \%$ to $\left.90 \%{ }^{\prime \prime}\right)$. Similar presentations were replicated in display cases throughout the school's hallways. No teacher or student could fail to be aware of the school's priorities, and every teacher we talked to referred to connections between their use of data and these three school

Figure 3. Presentation of School Goals at Jackson Middlle School

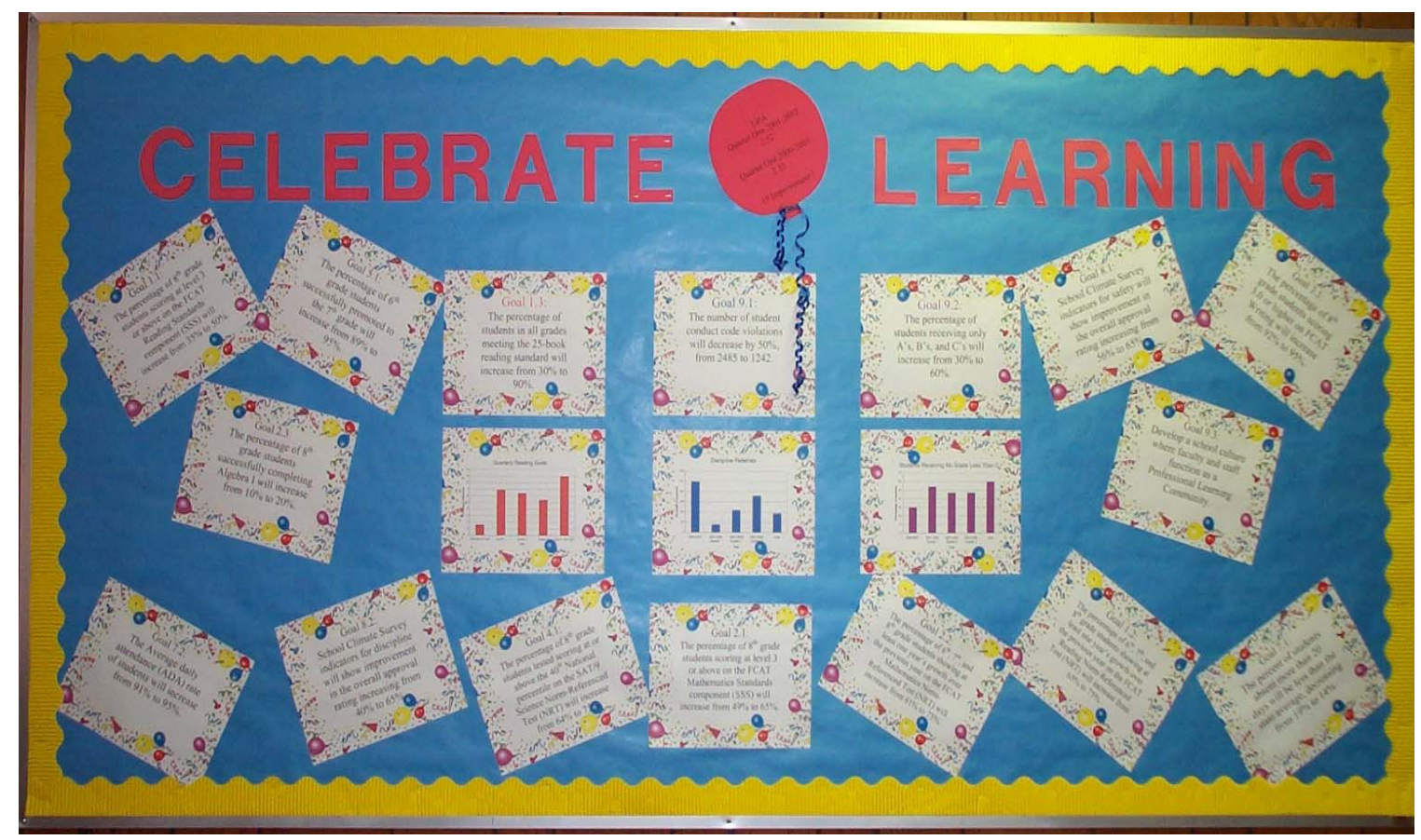


Figure 4. School Goals and Progress at Jackson Middle School

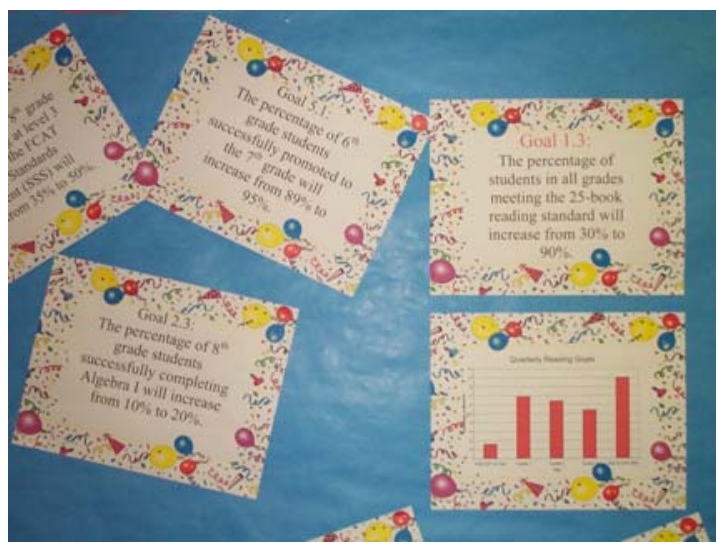

goals. "These are not just the goals for teachers and administrators," explained the school's assistant principal. "They are shared goals for students and faculty alike." These data were used in a variety of ways, many of which are described throughout this report. But, the point here is the way that school administrators used visual cues to focus attention and effort on three carefully considered priorities.

\section{Tracking Students in Need of Additional Support}

As discussed earlier, the schools in our sample used data to target lowperforming students for individualized support. However, in several of the schools, at-risk students, the intervention strategies used to encourage them to improve their performance, and their progress were chronicled on large posters. The posters also included recent test performance on both state and district assessments, with space for frequent updates, along with strategies for providing support to improve the performance of these students.

The enduring image of Parker Middle School, as shown in Figures 5 and 6, are the large charts that covered one wall of the principal's conference room, which was often the room used for leadership team and other adult meetings. The room, adjacent to the main office but behind the school secretary's desk, was off limits to students and the general public, thus

Figure 5. Principal's Conference Room at Parker Middle School

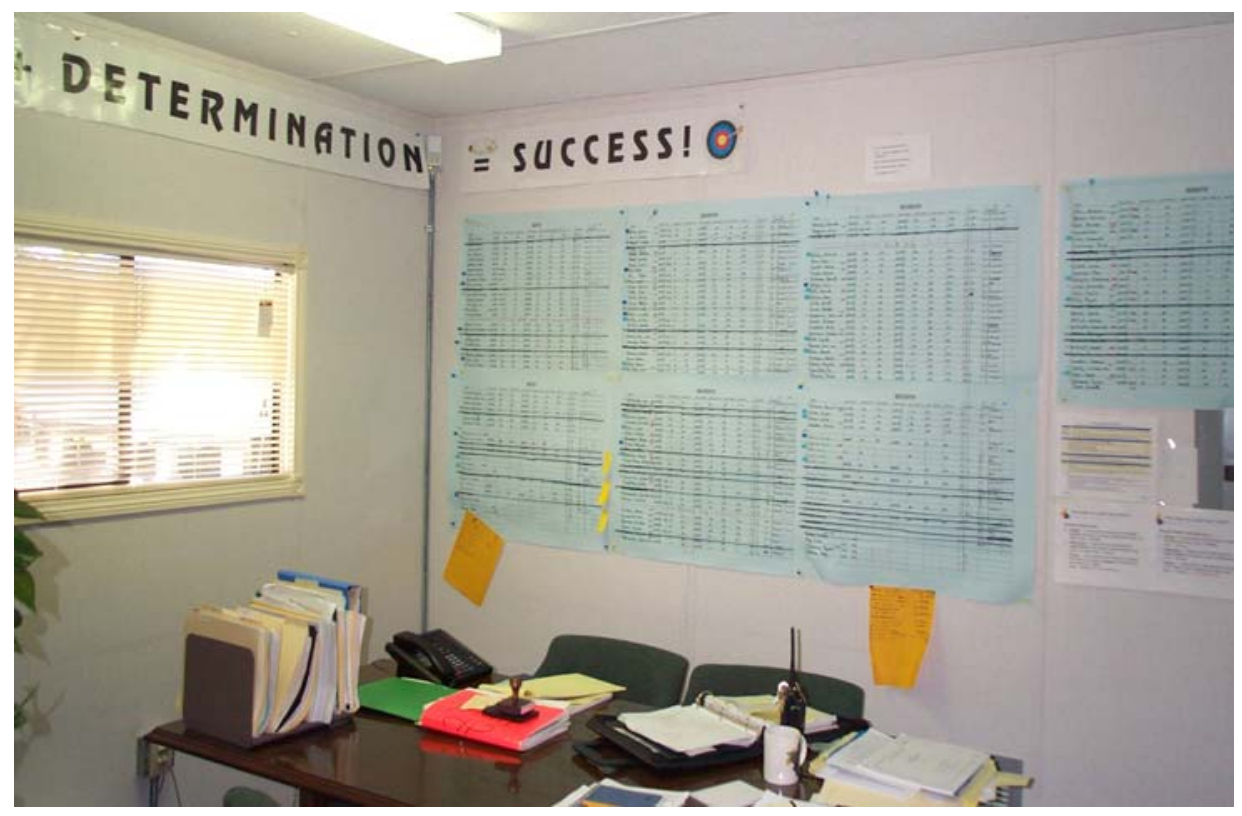


protecting the confidentiality of the data. Organized by grade level and subject, each poster listed all students who did not meet the state standard in either English, mathematics, or both. Along with student names, the posters included special status (special education, English language learner); reading, writing, and mathematics scores on the previous year's state test; number of books read by quarter; and space for comments. In the comments column were listed grades on more recent assessments, support programs that the student was assigned to, and even the names of individual adults who were responsible for encouraging and monitoring that student's progress. The columns were cluttered with entries and notes in different handwritings, which indicated that these were not wall decorations, but tools in daily use. These posters served as an ongoing reminder of the school's focus on improving the learning of even the most challenging students.

\section{Revealing Patterns in the Data}

By creatively rearranging numbers into pictures, teachers and school administrators can explore patterns within data
Figure 6. Tracking At-risk Students at Parker Middle School

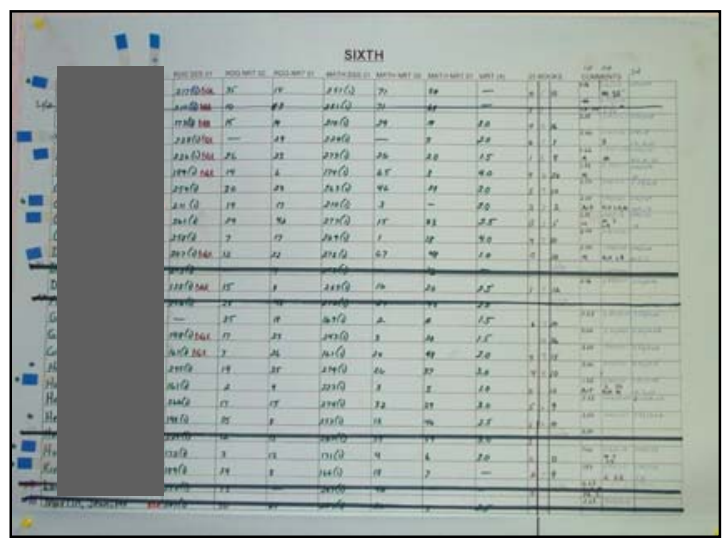

in order to gain insight into the influence of their efforts on student learning, and make adjustments accordingly. One of the most effective organizations of data that we discovered was the use of running record results at King Elementary School. Every quarter, teachers were expected to conduct running records on their students. The school's coach takes each teacher's running record results and graphs them cumulatively. Importantly, she is able to produce the results in a day. An example of a class's results is shown in Figure 7.

\section{Figure 7. Classroom Running Records Performance at King Elementary School}

Class X - Record of Reading Behavior

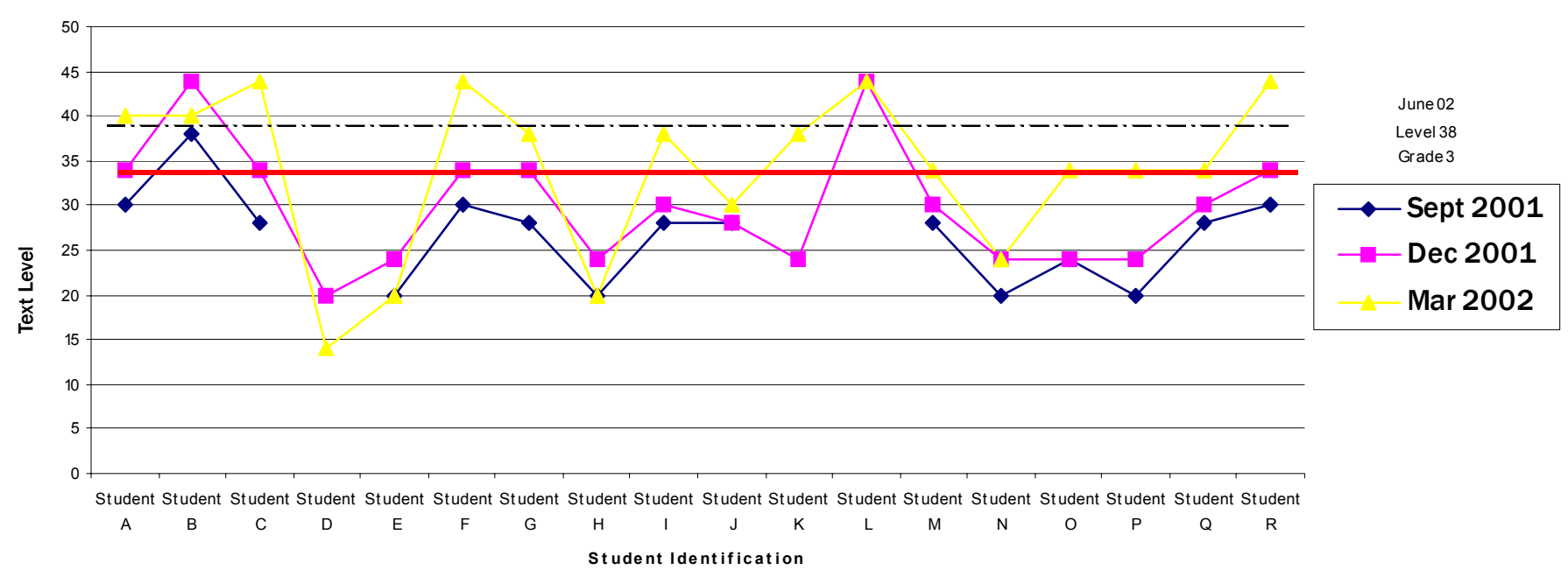


Each graphical representation would show each student's progress compared to the current expectation at that month as well as the end-of-year standard. According to the coach, the graphs reveal several things. They indicate which students are making progress, which are stagnating, and which are regressing. Additionally, the graphs reveal which students are on track toward standard and which students are at risk of not achieving the end-of-year expected reading level. These data, hot off the press, are used in several ways. First, teachers are able to adjust their instruction for sub-groups of students according to the results. Second, teachers are able to focus on individual students who may need more attention. Third, the coach meets with teachers to specifically discuss why some students may not be making adequate progress, which may result in additional services for those students and/or conversations with parents. Fourth, the data in aggregate are used to guide grade-level professional development.

Visual displays of data can make the imperceptible apparent, and can turn confusion into clarity. These three examples of visual presentations of data illustrate the power of the picture. By visually displaying data, school leaders can focus the attention of their faculty and students onto particular goals, reveal patterns that are otherwise barely visible, and provide insights that can guide the course of future action.

\section{Communicating with Parents}

Having student work on hand as well as a system that allows a teacher to show how the student's work has progressed over the course of the year is quite important for conversing with parents. It allows parents to understand the basis on which their child has been assessed as well as the types of work their child has been producing.
Data that are shared with parents allow information to flow beyond the classroom and school walls. When communicating with parents, it is important to give not only a picture of how a particular student is doing, or that student's work, but also an image of what the class has been working on and how that student's work is situated within the larger class. A fourth-grade teacher explained that, with respect to parents, she has an "open-door policy" in her classroom. She allows parents to not only get a picture of what is happening during class time, but she also shares "everything from her journals, all my notes, to my grade book." Allowing the parents access to data about their children, not only from external tests, but also from classroom practices, gives them a richer snapshot of how their children are learning and shows potential areas of struggle. Sharing classroom data with parents is helpful in both conferences with parents about their children and in the development of academic intervention plans, since parents are often included in such planning at this school.

Another seventh-grade English teacher described a system she uses in which she has an index card for each student. The card contains information such as reading levels and reading scores. Such a system allows for quick access to a lot of information and is useful for getting both detailed information about student progress as well as current standings. During parent conferences, the teacher "just pull[s] this [index card] out and here is the information right in front of me"

These examples allowed us to see that teachers use a variety of systems to collect data on their students. It is quite useful to be able to share these systems with parents as a means of communicating (beyond a report card) how a particular student is doing and by what means they are being assessed. Knowledge of this 
type is also a useful tool that allows parents further insight into ways in which they can help their children.

\section{Sowing the Seeds for Sustained Inquiry}

Knowledge comes, but wisdom lingers. (Alfred Tennyson, 1842)

Continuous inquiry into the relationships between different instructional practices and student learning in different forms and on different measures sharpens individuals' skills at diagnosing the meaning of data patterns and crafting appropriate instructional responses. Our discussions with the faculty at the five schools provided numerous examples of sustained and continuous, if bumpy, inquiry into the implications for practice stemming from evidence of student performance. Episodic examination of external data is formulaic and relatively superficial exactly because school leaders are not practiced at deciphering the puzzles and disjunctions that usually accompany regular data investigations.

We define inquiry as sustained investigations into the complex relationships between teaching and learning. Fullfledged inquiry involves a cyclical process whereby organizations focus on an important problem, devise a strategy to collect data to identify the particular source of the problem, analyze the data, take action based upon what is learned, and collect data to see if the action taken has influenced the identified problem (see, for example, Smith \& Ruff, 1998). This process is almost always interactive and recursive. Rarely are relationships obvious and clean. Questions often lead to more refined questions rather than definitive answers.

Learning theorists believe that adults learn best when investigating in groups (Preskill \& Torres, 1999; Wenger, 1998).
Group structures in education allow members not only to learn about content, but expose them to different interpretations and provide opportunities for discussion and refinement. Critical group examination of organizational performance data is seen as a cornerstone of the development of a learning organization (Mohrman \& Wohlstetter, 1994; Senge, 1990).

Based upon the stories we heard from the schools that we visited, these schools were developing into learning organizations. Their inquiries into their data stemmed from many sources. Several of the stories we heard about involved inquiries into data arose from discrepancies between different data sources. One often-mentioned discovery was a discrepancy between test scores and grades. As one assistant principal told us:

Very often, test scores and grades do not correlate. We find this often in our data. There are a lot of level 1 students who are making $A$ and $B$ on sheer effort. There are also a lot of level 4 students who are failing because they don't do the work. I've got a girl in eighth grade who has a 1.2 grade point average, who is reading on a college level.

Inquisitive leaders in our sample often asked questions that stemmed from the pictures that emerged from school data. For example, the principal of one elementary school wondered why her school was lauded as an exemplar of America's Choice implementation, yet student performance results were flat. She noted that her school had a high mobility rate and she wondered if the high mobility rate of students was masking gains for the stable sub-population. She told us:

I decided I was going to rise to that challenge, and I disaggregated the data for second grade and I looked at all the children that were here with us for the 


\section{Roosevelt Elementary School}

Leaders at Roosevelt Elementary School in New York City have used their data to unravel a puzzle. Why, they wondered, were their student performance levels flat after being recognized as one of the deepest-implementing America's Choice schools? After thoroughly examining their data, they speculated that high levels of student mobility may be masking the school's overall performance. "The data showed that the children who had been with us longest [when America's Choice was adopted] performed better than those who had not been with us for the three years," explained the principal.

The faculty at Roosevelt place a lot of emphasis on a variety of data. The school uses a plethora of data from both the state and district, as well as school-wide assessments. Individual teachers have ample flexibility to fill in gaps as they see fit. Given this cornucopia of data, the leadership team at Roosevelt has done a remarkable job of joining it all together into a coherent system that informs overall school and individual teacher practices.

The principal has played a crucial role in the development of this process. She has developed an analytic system that has allowed the faculty to look deeply at the data provided from test scores and recognized patterns throughout her school. Such practices have, for example, allowed the principal to see patterns regarding how bilingual students are achieving. Additionally, the principal uses the assessment data to create class profiles and to make goals for student achievement. A monthly assessment report is given to the superintendent.

The principal's role in developing and analyzing school data has led to a number of practices that are common throughout the classrooms at the school. In the beginning of the year, the teachers are required to give multiple reading assessments (developmental reading assessment, early childhood literacy development system, running records) and then triangulate the data to get an overall picture of where their students are. Along with these assessments, a system of benchmarks were developed by the school's leaders so that the teachers and staff agree upon targets for each classroom. Teachers are provided with training and encouraged to identify those children that are at risk and develop and monitor appropriate individualized improvement plans. The school's two assistant principals play a large role in helping to target and monitor at-risk students. The school has internalized an array of America's Choice formative assessment strategies to more thoroughly inform teachers about students' strengths and weaknesses. For example, over the past three years, considerable emphasis has been placed on the development of conferencing skills as a "very effective way to assess students." Running reading records are used to track and monitor students' reading and a Post-it note system allows teachers to create a picture of where their students are having trouble and then target those areas with mini-lessons.

In conjunction with systemic school-wide data structures, teachers are encouraged to develop their own assessment and student evaluation procedures and share them with their peers. While there were certain mandated record-keeping practices, teachers primarily dictated the information they kept. Emphasis was placed on teachers developing and then sharing their own successful strategies for assessing and assisting students. One administrator described the staff as a "self-motivated" group that "finds and creates forms and then shares them with the rest of the staff." 
three years and the ones that were more recent arrivals. And I charted my data again and I saw quite a difference. The data showed that the children who had been with us for the [longer] time performed better than those who had not been with us for the three years.

These conclusions provided important evidence to both the school's faculty and district leaders that the school's efforts were improving student learning.

At Jackson Middle School, school leaders were interested in understanding more about the students whose grades were low, but who had no trouble meeting the school reading goals and were not in any disciplinary trouble. According to the school's assistant principal:

We wanted to know why so many students weren't having discipline problems and were reading their 25 books, but somehow they made a grade less than $C$ on their report card. We wanted to know what is going on...something wasn't happening for them in the classroom. So [the principal] called those kids in and said, "You know, you guys didn't get a referral, you read your books, but yet you made either a $D$ or an $F$. What is going on?" And we found that for a lot of the kids, the D or F was not in their academic class. It was in P.E.! They just didn't want to dress out for physical education. In P.E., if you dress out you get at least a C. Most will get an A just because they put on their uniform. This age group, they don't like to change in front of other children. So, we went to the P.E. classes and told the children how important P.E. was. P.E. is not a requirement for promotion, but it is a required course and it is included in your GPA. Last year, the promotional requirement was a GPA of 1.8. We had a large number of kids who did not make the 1.8 because of P.E. A lot of kids with 1.79 , and that didn't count. It had to be 1.80. So these kids were not promoted, so they had to go to summer school. Well, they had $C$ averages in their academic courses already, but they failed P.E. But, in summer school, we only offer academic courses, so they had to retake the academic courses that they had already passed. So this year, we went to every P.E. class and told them how important it was that they dress out, that they participate, because now with it being 2.0, P.E. matters.

This inquiry into their data guided Jackson's administrators to a relatively simple adjustment to pay more attention to encouraging students to fulfill the physical education requirement — which allowed them to raise student passing rates and saved both students and the district the wasted effort and cost of unnecessarily attending summer school.

Perplexity is an important phase of discovery through inquiry. We encountered several cases in which individuals were confused by their data. As one teacher told us:

Sometimes data are just puzzling because I would look at the kids in my class and I would see that they are reading the books and I would look at their test scores and say, "This doesn't make sense." I just don't have the answers right now.

In other cases, data from different student performances produced contrary or inconsistent results. In such cases, teachers and school leaders did their best to reconcile the discrepancies in the data.

Ideally, such contradictions produce hypotheses that can be tested through future inquiries. Persistent people who regularly examine data from multiple sources use discrepancies between different data sources to catalyze inquiries into the reasons for these incongruities. As an example, the leaders at one elementary school described how anomalies between different data sources raised questions 
that led them to increase their focus on teaching comprehension skills in the primary grades. "We were trying to understand why kids were reading on grade level according to their running reading records, but they were not performing on the criterion test on comprehension on grade level," explained one school's literacy coach. In response, the school increased teachers' focus on comprehension at the end of first grade and the beginning of second grade as students started reading.

There is much learning to be had in the very process of extended inquiry into what produces student performance results. Not only are analytical skills practiced, but theories are crystallized, beliefs are made explicit, and expectations clarified. Explained one principal:

You get results when you pay attention to details that the data tells you. They can help guide you to what is important for students to know. We used to spend a lot of time on things - miniscule, little skills like sight words and how you add "es" or if they know the difference between a homonym and an antonym. We only have so many hours of instructional time...so you can't spend your time on everything; we have to spend our time on what's going to get us the most results.

Regularly practiced, inquiry can become recursive as questions lead to other questions. We found that those schools that regularly exercised their inquiry skills were those that developed systems to routinely and iteratively examine their data and ask questions from them. As one principal told us:

It is interesting that once the data inform you, they lead you down these paths that you wouldn't necessarily go down...It is very interesting when the discoveries you make correlate with something else you know from another source, then you know that you are on the right track, not necessarily the right answer, but you are heading toward the right place.

\section{The Role of Leadership}

We did not set out to examine the role of leadership in the data use of the schools in our sample, yet we would feel remiss not to mention the role that leadership played in many of the innovative activities that we heard about in our research. The fingerprints of strong leadership are all over the data activities in the schools in this study. Virtually every example of innovative data use in this study came from the initiative and enterprise of an individual who had the vision and persistence to turn a powerful idea into action. Whether it was the principal at Roosevelt Elementary School setting ambitious goals for her school and monitoring them continuously with her data, the assistant principal at Parker Middle School creating posters upon which to monitor the intervention strategies for at-risk students and their effects, the literacy coach at King Elementary School organizing the school's running record data into graphical patterns for grade-level analysis, the principal at Mendel Elementary School continuously exhorting her faculty to question the instructional practices that were producing their student performance results, or the teachers/team leaders at Jackson Middle School who took charge of maintaining electronic databases of the grades and reading accomplishments of students on their teams, leaders breathed meaning into their data. Leadership, wherever it emanates from, seems complicit in excellence.

While examples of inventive data use came from both formal and informal leadership within the schools we examined, in most cases, the principal was the driving force behind strong data use. In several of the sites, we got the sense that it was the principals' constant emphasis on data that turned the data from numbers on a page into action in the classroom. As one principal described her role: 
I guide the teachers a lot in where we're going with the data...if I didn't ask the question, "Why are these kids having such trouble in this area?" then the teachers would just say, "She [principal] wants us to give these tests so I gave them and then put them on the shelf." I am constantly saying, "How are you using the results? Or tell me why this child is having such difficulty in this area"...Things like that, they need to look at. They're getting much more savoy at it because they have notebooks where they're keeping information on their conferencing and things like that, but...I think if I backed off completely, they wouldn't look at it that much.

In another elementary school, the principal went so far as to develop a highly customized system to facilitate teachers' analyses of their students' performance data. She developed a personalized folder for each fourth-grade teacher in the school (fourth grade being the high-stakes test grade), which included the previous year's test results for each child in the class with a breakdown of the skills the teacher needed to work on for each child, as well as the previous year's reading data for that child. Further, the principal used these analyses to project which level each student would be on the state test the next year and what would be required to bring them up to the next level. She then sat down with each fourth-grade teacher and developed lesson sequences intended to move students to the next level on the state test.

Regardless of whether it emanates from the principal or other school leaders, in order for data to be used sustainedly, leaders must buy in and provide the necessary resources and advocacy to encourage faculty to make the extra effort to use data on a regular basis.

\section{What It Takes to Use Data Systematically}

Systematically using data takes a commitment on many levels. Schools that seek to use data more effectively will need more time, training, technology, and discipline.

Every school in our study committed a substantial amount of time for using data. Essentially, each school had a single individual who was assigned to collecting and monitoring the data and that individual spent a lot of time manipulating the data. As one school's data manager recalled:

...every time they get any kind of data from the district office or from state, we go ahead and we get that in a format that is something the teachers can use because sometimes the way it comes to us, it's just gobbledygook, and we have to break that down and then it is continually monitored, continually updated, and given to teachers.

The school leaders felt that it was time consuming to manage their student performance data. One typical comment was:

It is, it is hard to sit at my desk and put all this together. I was with a parent yesterday and I was saying, "I can tell every child in this building who is in danger of summer school, who might be eligible and who is not"...And she said, "When do you find the time to know all of this about your kids and still have a life outside your building?" I spend a lot of evenings here when it is time to update my database. It will take me an entire day to update. 
Theoretically, school leaders could reduce the burden on themselves for managing data by distributing the responsibility across multiple people within a school. In one case, for example, team leaders were responsible for keeping an updated database of the performance of students on their team. But generally, the principals and assistant principals in our study were reticent to distribute the responsibility to other members of the school faculty. One typical response was:

I have found that every time I have tried to do that, it has gotten messed up. When I ask for support from the house administrators, I am finding there are a lot of mistakes. For example, there was one child that came to Saturday school for language arts and went the whole three weeks and she had Cs in language arts. She had Fs in math. She should have been in math. But the person who put her on the list wrote down the wrong subject. And that was very upsetting to me and the girl that she did it for nothing.

In order to make data use feasible, a school must take advantage of computer technology. Nonetheless, we were shocked to observe the limited technological capacity of even these innovative data-using schools. One might expect that these schools might have had a technology guru to manipulate their data, but we can recall no case from any of these schools where the individual processing the data was exceptionally technologically sophisticated. In fact, it was just the opposite. In most cases, the things that they were doing with their data was the product of sheer effort and they were using extremely inefficient methods to process data. For example, some schools were putting data into tables and using word-processing sorting functions rather than taking advantage of a spreadsheet or database functions. Administrators knew that these capabilities were available, but did not know how to use them. Nor did they know how to easily get information to do what they wanted to do. Several administrators felt that they could get any test data that the district collected from their district research office, but did know in what form it would be most useful. Finally, for those few that were interested in developing their own assessments, they needed assistance with developing a constructive and productive process to do this.

Our wider sample of school leaders similarly felt that they lacked the technical expertise to analyze student performance data. In our 2002 survey, only 19\% of the respondents felt that they had the technical skills to manipulate the data in order to use it to answer questions that they wanted to ask. Thus, beyond the admirable efforts of a select few individuals, if a school is to reasonably expect to use data more systematically, then they must have the technological capacity to organize and manipulate student performance data and have better access to training to take advantage of technological capacity.

Finally, it should be acknowledged that more extensive data use will likely produce resistance from uncommitted faculty members. No one likes their work to be scrutinized by others, even if we appreciate the constructive feedback that helps us improve our craft. We only heard of a few cases of resistance to data use in this study, likely because the schools in our sample were selected precisely because of their data innovations and the teachers we interviewed were selected by their principals as more sophisticated practitioners. Even so, the accountability that is implicit in more refined examinations of data will likely produce resistance, in some form, from some faculty members as they get used to the idea of publicly examining their practices. 


\section{Framework for a System of School Data Use}

One of the major themes of this report is that there are potentially both a rich array of data available to teachers and leaders within their schools and a multitude of ways in which those data can be used for instructional guidance, institutional planning, organizational support, and cultural influence. Most of the data available to schools goes unexamined. Yet, data can provide a solid bedrock from which to base well-considered courses of action and to test whether past decisions have paid off.

One of the potentially powerful resources for informing instructional and school improvement - school-wide data - is enormously underutilized. The distinguishing characteristics of schoolwide data are that they are frequently and systematically collected across a grade level or content area about an important student outcome and quickly aggregated and examined for patterns that can help inform next steps. School-wide data should be nimble numbers that provide meaningful guidance for finer-grained adjustments. Our conception of schoolwide data incorporate the formative qualities of assessment by providing opportunities for the examination of data patterns both within and across classrooms and using the results for organizational decision-making and refinement. School-wide data, therefore, are intended to provide guidance beyond the individual teacher. Yet, while school-wide data are intended to be more generalizeable than formative assessments, providing feedback to teachers, grade levels, and school administrators, they are not intended to be used for highstakes decision-making. Therefore, while these characteristics are still important and should be attended to, they do not need to meet the more rigorous validity and reliability criteria of their external assessment brethren. Examples of schoolwide data are relatively scarce, but the running records institutionalized in America's Choice schools, systematically administered at least quarterly by all teachers, and which can easily be aggregated and provide fine-grained guidance, offer a concrete model for the potential of school-wide data.

Given the three sources of data and the myriad possible uses, how should school leaders think about making appropriate uses of each of the three sources? One useful way to make sense of each of these sources is to consider the potential uses for each one. Table 1 shows one way that school leaders can think of making appropriate use of the different data sources available to them.

To chart a course for school improvement, external data are a way to set one's bearings, a starting place, a general roadmap, and a destination. External assessment results are primarily intended to be used for accountability purposes outside of the school and should be understood as such. From the school's perspective, they provide some useful information, but their utility is limited. While school leaders and teachers can glean much information from them, they are not designed to be frequent and specific enough to provide the timely and fine-grained information necessary for precise instructional guidance and feedback. They provide initial direction, topics for early professional development, and help identifying students in need of additional support, and to set long-term performance goals. They are useful for benchmarking global school performance against other similar schools and provide an occasion for celebration. Their utility largely comes from their use as a point of embarkation.

School-wide assessments are a more calibrated compass to guide schools on the path toward improvement. They 
Table 1. Sources and Uses of Student Performance Data

\begin{tabular}{|c|c|c|}
\hline Source & Examples & Uses \\
\hline $\begin{array}{l}\text { External } \\
\text { Assessments }\end{array}$ & $\begin{array}{l}\text { State \& District } \\
\text { Assessments }\end{array}$ & $\begin{array}{l}\text { - Benchmarking against similar schools } \\
\text { - Providing initial direction } \\
\text { - Aligning instruction with external content } \\
\text { - Setting annual goals } \\
\text { - Planning initial professional development } \\
\text { - Identifying low-performing students and } \\
\text { developing assistance plans for them } \\
\text { - Celebrating accomplishments } \\
\text { - Developing a culture of inquiry }\end{array}$ \\
\hline $\begin{array}{l}\text { School-wide } \\
\text { Assessments }\end{array}$ & $\begin{array}{l}\text { Running Records } \\
\text { Theme Tests } \\
\text { Uniform Writing Examples } \\
\text { Grades }\end{array}$ & $\begin{array}{l}\text { - Providing cross-grade/subject guidance } \\
\text { throughout the school year } \\
\text { - Refining professional development } \\
\text { - Refining assistance plans for low- } \\
\text { performing students } \\
\text { - Reinforcing culture of inquiry }\end{array}$ \\
\hline $\begin{array}{l}\text { Individual Teacher } \\
\text { Assessments }\end{array}$ & $\begin{array}{l}\text { Portfolios } \\
\text { Writing Folders } \\
\text { Conference Logs } \\
\text { Reading \& Writing Journals }\end{array}$ & $\begin{array}{l}\text { - Providing quick and flexible feedback } \\
\text { throughout the year } \\
\text { - Allowing for opportunistic adjustments in } \\
\text { instruction and targeted assistance } \\
\text { - Individualized to particular style and } \\
\text { needs of classroom teacher }\end{array}$ \\
\hline
\end{tabular}

allow teachers and school leaders to check their location and redirect their course based upon updates of their current position. School-wide assessments can provide more fine-grained guidance throughout the school year. They allow teachers to refine their instructional strategies based upon detailed feedback and provide school leaders with timely feedback to adjust professional development strategies and refine assistance plans for individual students. Further, school-wide assessments provide valuable opportunities for faculty to inquire together into the relationships between practice and learning. Such group inquiries can become part of the cultural glue that holds a school together.

For teachers, individual assessments can be like having a personal global positioning system. They are the most precise and customized of assessments. When used well by teachers, they can provide highly tailored and flexible feedback. Individualized to the particular style and needs of the individual classroom teacher, they are often composed and recorded in a language that only their authors understand.

In the modal school, we believe that the uses of data are formulaic, episodic, and superficial. The previous year's test results are presented to the faculty at the beginning of the school year and are only examined shallowly. Targets are written into the school improvement plan that are based upon guesses. No one really has confidence in the planning based on the past year's results because the students are not the same students, the generalizations are problematic because of small sample sizes, and the pre-packaged ways that the data are decomposed are not meaningful to the faculty for whom they are intended. 


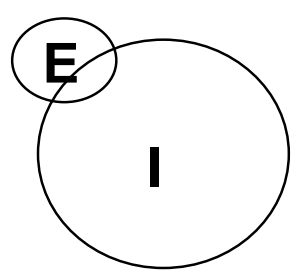

Figure 8.1

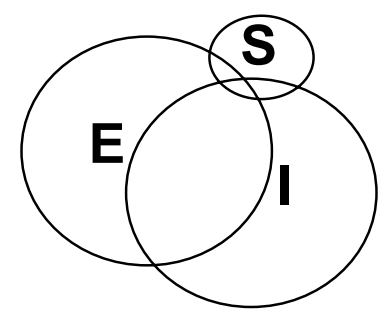

Figure 8.2

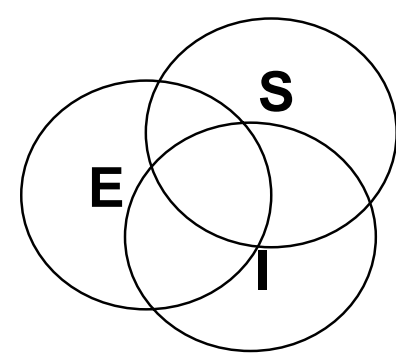

Figure 8.3
Consider one's own school or a school that one knows well. What is the relative emphasis on using external test data relative to school-wide or individual teacher data? We believe that two common situations are represented in Figures 8.1 and 8.2. In Figure 8.1, a school makes some limited use of external assessment data (E) while teachers use a wide variety of individual assessments (I) within their classrooms. There are no school-wide assessments (S) in the school represented in Figure 8.1. In Figure 8.2, the school makes strong use of external assessments (E), with some small use of school-wide assessments (S). There are some cases of school-wide data use in these schools, but these cases are both relatively uncommon and underdeveloped. Again, teachers use a wide variety of individual assessments (I) within their classrooms. The schools examined in this study were closer to those represented in Figure 8.2, even though they were chosen as the most innovative, data-using schools available. This supports our contention that even those schools with relatively sophisticated use of data have only partially evolved into schools with systematic data use.

A school with systematic data use is represented in Figure 8.3. In this school, external data are milked for as much information as they can provide. Schoolwide assessments, carefully selected or developed to meet reasonable standards of validity and reliability, are used to provide teachers and administrators with feedback along the way toward the endof-year high-stakes assessment. These data serve to confirm, disconfirm, or raise questions about the results on the external assessment and contribute to the cultural identity of the school as a datadriven learning organization. All the while, teachers, trained in the craft of assessment construction and use, are encouraged to develop and implement their own individualized systems to collect and analyze student performance data in a variety of creative ways within their classrooms.

We believe that schools with effective school data systems would look like Figure 8.3, consisting of three interwoven and mutually reinforcing components. Together, these three assessment forms have the potential to drive schools forward and support their efforts along the way. External assessments provide the targets for schools to strive toward and the data from which to set initial direction and goals. School-wide assessments are more refined; they can provide schools with guidance along the path toward external assessments that allow schools to adjust their direction and strategies along the way. Individual assessments are the opportunities for personal expression, giving teachers the day-to-day guidance that any good teacher would desire in their classroom. The ultimate purpose of an intertwined system of assessment built upon different data sources with different 
uses is to develop and exercise the habits of inquiring into the complex meaning of student results as they relate to the instructional practices of teachers and the organizational capacity-building strategies of school leaders. By incorporating the regular examination of student performance into the routines of the school year, teachers and school leaders can continually grow and refine their professional expertise. Together, they can form a powerful and mutually supportive school data system.

Of course, there are many potential potholes along this road. What if external assessment results are inconsistent with school-wide assessments? What if the results on school-wide tests seem inconsistent with each other? Are they measuring the same thing? Is one of them giving a false read? What if the results of an assessment are confusing or do not indicate a clear course of action? What if the guidance from the results is too vague to provide useful direction? What if the skills to determine patterns are rudimentary in the staff? These are all very real dilemmas.

But these problems actually point to two inherent strengths of a school data system. First, rather than relying on no evidence at all, or on a single indicator of performance to guide action, the development of a school data system allows school leaders to triangulate across multiple forms of evidence and develop and sustain a culture of inquiry. The focus on multiple forms of assessment, administered and analyzed more frequently, rather than solely the annual high-stakes external tests, creates a greater balance and in some ways reduces the stakes associated with that single high-stakes event. The multiple forms of assessment reduce the anxiety of relying on a single measure as the sole definition of success. Within the school, the availability of multiple data sources of student performance provides administrators and teachers with more frequent evidence with which to act. The confirming or disconfirming of results can provide stronger evidence to support fundamental conclusions or call them into question.

This leads to the second strength of an assessment system, which is that their pursuit of answers to the kinds of questions posed above are a healthy form of inquiry into the relationship between the strategies, resources, and organizational decisions that teachers and school leaders employ and the learning of students. The engagement of a school faculty into the meaning of their student performance data and how it relates to what they do in their classrooms is a powerful and productive journey.

\section{Conclusion}

There are countless entry points into a school faculty's discussion of how they can improve the quality of education within their domain. Using student performance data as the portal to improving teaching and learning is particularly promising because it focuses the conversation around the student learning outcomes of the organization and connects to so many of the crucial activities that influence those learning outcomes. Issues of curriculum, pedagogy, equity, professional development, the use of time, the organization of the school, and the role of parents and the community, all influence the learning gains that students make. Even if the mix is so complex and the measures so imprecise that replicable concrete connections remain elusive, the ensuing conversation and pointed experimentation in itself produces constructive change.

Yet, ultimately, to undertake data investigation most rigorously, school faculties are at the mercy of our broader, culturally entrenched conceptions of what it means to be professional educa- 
tors. The prevailing view is that teachers are only on the job as long as they are in front of students. Yet, any serious investigations into student performance data require that teachers learn and practice more sophisticated skills and spend more time conducting analyses and designing responses than are currently available. What profession, other than K-12 teaching, spends more time performing than preparing for performance? Systematic data analysis is about more carefully preparing for performance. Implicit to this idea is that systematic analysis of how teaching produces learning is at the core of teachers' inquiry into how to continually improve their practice. Yet, the structures and opportunities to engage in these inquiries are virtually absent in the American system of education. Only when this occurs on a widespread basis can American education come closer to reaching its goal of improving the learning outcomes of all students. 


\section{References}

Black, P., \& Wiliam, D. (1998). Inside the black box: Raising standards through classroom assessment. Phi Delta Kappan, 80(2), 139-148.

Eliot, T. S. (1934). The Rock (Line 1).

Huxley, T. H. (1895). On elementary instruction in physiology. Collected Essays, 3.

Johnson, S. (1775). As cited in Boswell, J., (1791). The life of Samuel Johnson, 2, 365.

Kennedy, M. M. (1998, April). The relevance of content in inservice teacher education. Paper presented at the annual meeting of the American Educational Research Association, San Diego, CA.

Little, J. W. (1993). Teachers' professional development in a climate of educational reform. Educational Evaluation and Policy Analysis, 15(2), 129-151.

McLaughlin, M. W., \& DarlingHammond, L. (1995). Policies that support professional development in an era of reform. Phi Delta Kappan, 76(8), 597-604.

Mohrman, S. A., \& Wohlstetter, P. (Eds.) (1994). School-based management: Organizing for high performance. San Francisco: Jossey-Bass Publishers.

National Center on Education and the Economy. (2001). Comprehensive reform designs. Washington, DC: Author.

Preskill, H., \& Torres, R. T. (1998). Evaluative inquiry for learning in organizations. Thousand Oaks, CA: Sage Publications.

Senge, P. (1990). The fifth discipline: The art and practice of the learning organization. New York: Doubleday.
Smith, D., \& Ruff, D. (1998). Building a culture of inquiry: The school quality review. Assessing student learning: From grading to understanding. New York: Teachers College Press.

Supovitz, J. A., Poglinco, S. M., \& Bach, A. (2002). Implementation of the America's Choice literacy workshops. Philadelphia: Consortium for Policy Research in Education, University of Pennsylvania.

Tennyson, A. (1842). Locksley Hall (Line 178).

Wenger, E. (1998). Communities of practice: Learning, meaning, and identity. Cambridge: Cambridge University Press.

Wiggins, G., \& McTighe, J. (1998). Understanding by design. Upper Saddle River, NJ: Merrill Prentice Hall.

Wolf, D. P., \& Reardon, S. F. (1993, March). Equity in the design of performance assessments: A handle to wind up the tongue with? Paper presented at the Ford Foundation symposium on equity and educational testing and assessment, Washington, DC. 


\section{About the America's Choice Design}

The America's Choice school design is a K-12 comprehensive school reform model developed by the National Center on Education and the Economy (NCEE). America's Choice is a well-established school reform model currently being implemented in over 500 schools across the nation. America's Choice focuses on raising academic achievement by providing a rigorous standards-based curriculum and safety nets for all students. A stated goal of America's Choice is "to make sure all but the most severely handicapped students reach an internationally benchmarked standard of achievement in English/language arts and mathematics by the time they graduate" (National Center on Education and the Economy, 2001, p. 1).

The core of the America's Choice design contains a set of principles about the purpose of schooling and how schools should operate, and it provides a set of tools for building a program based on those principles. These essential principles and tools include:

- High expectations for all students, with communication of those expectations through explicit performance standards that are aligned to assessments and include examples of student work that meet the standards.

- The implementation of standardsbased literacy and math blocks, which happen every day for every child, and dramatically change teaching and learning in every classroom. The rituals and routines associated with these blocks are designed to prepare students to deal with demanding content and become independent learners.
- Ongoing assessment of students in order to inform daily instruction.

- School-embedded, ongoing, teacher professional development led by a full-time literacy coach designed to strengthen teachers' knowledge of the America's Choice approach to teaching and learning. This includes learning how to conduct a close analysis of their students' work in relation to standards, and using this knowledge to develop lessons calibrated to the needs of different students.

- Standards-based curriculum and instructional strategies that help students develop key skills, convey core concepts, and apply what they know.

- A school leadership team, led by the principal and subject-matter coaches, that coordinates implementation through a variety of means. These include setting performance targets and analyzing student work on a variety of measures, training teachers, adjusting school schedules, and implementing safety-net programs to provide time for students to receive additional instruction.

- "Safety nets," including tutoring and course recovery programs, that are structured into the school day and school year, and that provide students with extensive support and multiple opportunities to achieve the standards. 


\section{About CPRE's Evaluation of America's Choice}

The Consortium for Policy Research in Education (CPRE) at the University of Pennsylvania was contracted by NCEE in 1998 to conduct the external evaluation of the America's Choice school design. Each year, CPRE designs and conducts a series of targeted studies on the implementation and impacts of the America's Choice design.

The purpose of CPRE's evaluation is to provide formative feedback to NCEE and America's Choice schools about emerging trends in the implementation of the design, and to seek evidence of the impacts of the design using accepted high standards of evaluation design and analysis methodologies.

CPRE's evaluation of America's Choice is guided by three overarching evaluation questions. First, is America's Choice being carried out in the manner envisioned - that is, how are teachers and school administrators understanding and implementing the many facets of the reform design? Second, as a result of the implementation of America's Choice, are the instructional practices of teachers changing in ways that would improve student learning? Third, to what degree can improvements in student achievement be attributed to the design? Within this framework, annual evaluation studies target specific aspects of the America's Choice design for more in-depth investigation. To address these questions, the CPRE evaluation team gathers a broad array of qualitative and quantitative data to develop a rich and valid picture of the implementation process over time and to capture the impacts of the design on students and teachers. Data sources include:
- Surveys of teachers and administrators in America's Choice schools nationwide.

- Site visits to schools across the nation to observe classroom instruction, examine implementation artifacts, and interview teachers, students, and school administrators.

- Telephone interviews with NCEE staff, school faculty members, and school and district administrators.

- Document reviews.

- Observations of national, regional, and school-level professional development.

- Collection of student performance measures, including state and local tests, the New Standards Reference Examination, and more authentic samples of student work products.

After data collection, CPRE research team members analyze the data using appropriate qualitative and quantitative research techniques in order to identify patterns of intended and unintended consequences and to detect effects of the design on students, teachers, and schools. The results are reported in a series of thematic evaluation reports that are released each year. 


\section{Additional Reading on America's Choice}

The following reports are currently available from CPRE. Print copies are available at no cost by emailing cpre@gse.upenn.edu, or by calling 215-573-0700. Copies can also be downloaded at www.cpre.org/Research/ Research_Project_America's_Choice.htm.

- Teacher and Coach Implementation of Writers Workshop in America's Choice Schools, 2001 and 2002 (Amy J. Bach and Jonathan A. Supovitz, October 2003)

- The Heart of the Matter: The Coaching Model in America's Choice Schools (Susan M. Poglinco, Amy J. Bach, Kate Hovde, Sheila Rosenblum, Marisa Saunders, and Jonathan A.

Supovitz, May 2003)

- The Relationship Between Teacher Implementation of America's Choice and Student Learning in Plainfield, New Jersey (Jonathan A. Supovitz and Henry May, January 2003)

- Impact of America's Choice on Student Performance in Duval County, Florida (Jonathan A. Supovitz, Brooke Snyder Taylor, and Henry May, October 2002)

- Implementation of the America's Choice Literacy Workshops (Jonathan A. Supovitz, Susan M. Poglinco, and Amy J. Bach, April 2002)

- Instructional Leadership in a Standards-based Reform (Jonathan A. Supovitz and Susan M. Poglinco, December 2001)
- Moving Mountains: Successes and Challenges of the America's Choice Comprehensive School Reform Design (Jonathan A. Supovitz, Susan M. Poglinco, and Brooke Snyder, March 2001)

- America's Choice Comprehensive School Reform Design: First-year Implementation Evaluation Summary (Thomas Corcoran, Margaret Hoppe, Theresa Luhm, and Jonathan A. Supovitz, February 2000) 